\title{
QUEEN'S
UNIVERSITY
BELFAST
}

\section{Sum frequency generation spectroscopy of tetraalkylphosphonium ionic liquids at the air-liquid interface}

Peñalber-Johnstone, C., Adamová, G., Plechkova, N. V., Bahrami, M., Ghaed-Sharaf, T., Ghatee, M. H., Seddon, K. R., \& Baldelli, S. (2018). Sum frequency generation spectroscopy of tetraalkylphosphonium ionic liquids at the air-liquid interface. Journal of Chemical Physics, 148(19), [193841].

https://doi.org/10.1063/1.5009674

Published in:

Journal of Chemical Physics

Document Version:

Publisher's PDF, also known as Version of record

Queen's University Belfast - Research Portal:

Link to publication record in Queen's University Belfast Research Portal

Publisher rights

(c) 2018 The Authors. This work is made available online in accordance with the publisher's policies. Please refer to any applicable terms of use of the publisher.

\section{General rights}

Copyright for the publications made accessible via the Queen's University Belfast Research Portal is retained by the author(s) and / or other copyright owners and it is a condition of accessing these publications that users recognise and abide by the legal requirements associated with these rights.

Take down policy

The Research Portal is Queen's institutional repository that provides access to Queen's research output. Every effort has been made to ensure that content in the Research Portal does not infringe any person's rights, or applicable UK laws. If you discover content in the Research Portal that you believe breaches copyright or violates any law, please contact openaccess@qub.ac.uk. 


\section{Sum frequency generation spectroscopy of tetraalkylphosphonium ionic liquids at the air-liquid interface}

Chariz Peñalber-Johnstone, Gabriela Adamová, Natalia V. Plechkova, Maryam Bahrami, Tahereh GhaedSharaf, Mohammad Hadi Ghatee, Kenneth R. Seddon, and Steven Baldelli

Citation: The Journal of Chemical Physics 148, 193841 (2018); doi: 10.1063/1.5009674

View online: https://doi.org/10.1063/1.5009674

View Table of Contents: http://aip.scitation.org/toc/jcp/148/19

Published by the American Institute of Physics

\section{Articles you may be interested in}

Nonlinear optical response of a gold surface in the visible range: A study by two-color sum-frequency generation spectroscopy. I. Experimental determination

The Journal of Chemical Physics 148, 134701 (2018); 10.1063/1.5021553

Atmospheric pressure reaction cell for operando sum frequency generation spectroscopy of ultrahigh vacuum grown model catalysts

Review of Scientific Instruments 89, 045104 (2018); 10.1063/1.5021641

A Highly Sensitive Femtosecond Time-Resolved Sum Frequency Generation Vibrational Spectroscopy System with Simultaneous Measurement of Multiple Polarization Combinations

Chinese Journal of Chemical Physics 30, 671 (2017); 10.1063/1674-0068/30/cjcp1706114

Molecular dynamics study of structure and vibrational spectra at zwitterionoic lipid/aqueous $\mathrm{KCl}, \mathrm{NaCl}$, and $\mathrm{CaCl}_{2}$ solution interfaces

The Journal of Chemical Physics 148, 222801 (2018); 10.1063/1.5006543

Temperature dependence of water-water and ion-water correlations in bulk water and electrolyte solutions probed by femtosecond elastic second harmonic scattering

The Journal of Chemical Physics 148, 222835 (2018); 10.1063/1.5023343

Vibrational sum-frequency generation spectroscopy of lipid bilayers at repetition rates up to $100 \mathrm{kHz}$

The Journal of Chemical Physics 148, 104702 (2018); 10.1063/1.5016629

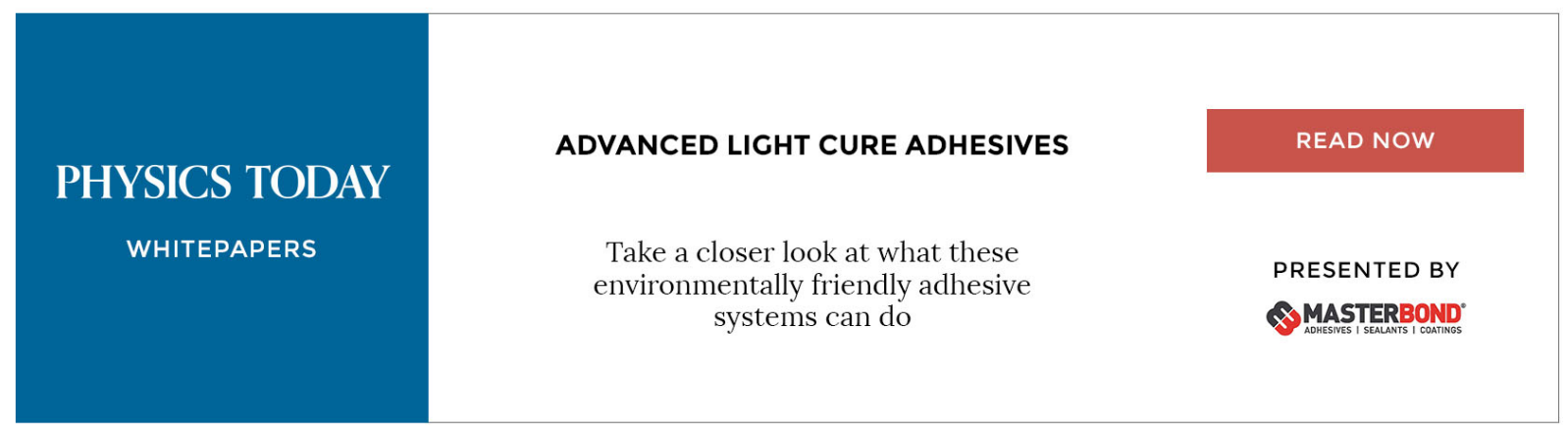




\title{
Sum frequency generation spectroscopy of tetraalkylphosphonium ionic liquids at the air-liquid interface
}

\author{
Chariz Peñalber-Johnstone, ${ }^{1}$ Gabriela Adamová, ${ }^{2}$ Natalia V. Plechkova, ${ }^{2}$ Maryam Bahrami, ${ }^{3}$ \\ Tahereh Ghaed-Sharaf, ${ }^{3}$ Mohammad Hadi Ghatee, ${ }^{1,3}$ Kenneth R. Seddon, ${ }^{2, a)}$ \\ and Steven Baldelli $i^{1, b)}$ \\ ${ }^{1}$ Department of Chemistry, University of Houston, Houston, Texas 77204-5003, USA \\ ${ }^{2}$ QUILL Research Centre, The Queen's University of Belfast, Belfast BT9 5AG, \\ Northern Ireland, United Kingdom \\ ${ }^{3}$ Department of Chemistry, Shiraz University, Shiraz 71946, Iran
}

(Received 18 October 2017; accepted 8 March 2018; published online 5 April 2018)

\begin{abstract}
Sum frequency generation (SFG) spectroscopy is a nonlinear vibrational spectroscopic technique used in the study of interfaces, due to its unique ability to distinguish surface molecules that have preferential ordering compared to the isotropic bulk. Here, a series of alkyltrioctylphosphonium chloride ionic liquids, systematically varied by cation structure, were characterized at the air-liquid interface by SFG. The effect on surface structure resulting from molecular variation (i.e., addition of cyano- and methoxy-functional groups) of the cation alkyl chain was investigated. SFG spectra in the $\mathrm{C}-\mathrm{H}$ stretching region $\left(2750-3100 \mathrm{~cm}^{-1}\right)$ for $\left[\mathrm{P}_{88_{8}}\right][\mathrm{Cl}]$, where $n=4,5,8,10,12$, or 14, showed characteristic changes as the alkyl chain length was increased. Spectral profiles for $n=4,5,8$, or 10 appeared similar; however, when the fourth alkyl chain was sufficiently long (as in the case of $n=12$ or $n=14$ ), abrupt changes occurred in the spectra. Molecular dynamics (MD) simulation of a slab of each ionic liquid (with $n=8,10$, or 12) confirmed gauche defects, with enhancement for the long alkyl chain and an abrupt increase of gauche occurrence from $n=8$ to $n=10$. A comparison of the tilt angle distribution from the simulation and the SFG analysis show a broad distribution of angles. Using experimental SFG spectra in conjunction with MD simulations, a comprehensive molecular picture at the surface of this unique class of liquids is presented. Published by AIP Publishing. https://doi.org/10.1063/1.5009674
\end{abstract}

\section{INTRODUCTION}

Phosphonium ionic liquids, although not as well studied as 1,3-dialkylimidazolium salts, offer important advantages in applications such as its low cost of preparation, ${ }^{1}$ high thermal stability, ${ }^{2,3}$ better lubrication and anti-wear ability, ${ }^{4}$ and low potential for interaction with various solutes. The latter is advantageous because unlike their 1,3-dialkylimidazolium analogues, tetraalkylphosphonium ionic liquids lack acidic protons or aromatic rings and are thus good for applications requiring relatively inert reaction media.

Over the past several years, the literature reports on the synthesis and basic physicochemical properties of phosphonium ionic liquids have grown. ${ }^{1,5-11}$ However fundamental studies on the extent of structuring present in quaternary phosphonium ionic liquids remain quite limited. ${ }^{12}$ The more recent accounts of the behavior of these salts include solvation, ${ }^{13,14}$ transport and thermal properties, ${ }^{15,16}$ and solubility and phase behavior. ${ }^{17}$ Consequently, the unique qualities of this class of materials known so far have found value in several applications such as in extractions, ${ }^{18,19}$ separations,${ }^{20}$ catalysis, ${ }^{21}$ synthesis of new materials, ${ }^{22,23}$ electrochemistry, ${ }^{24,25}$ and lubrication. ${ }^{26}$

\footnotetext{
a)Deceased.

b)Author to whom correspondence should be addressed: sbaldelli@uh.edu.
}

An important surface study on phosphonium-based ionic liquid has recently been conducted by Licence et al. using $\mathrm{X}$-ray photoelectron spectroscopy. ${ }^{27}$ In these investigations, the authors conclude that the surface of the ionic liquidvacuum interface is complicated and that the alkyl chains effectively shield the charge $\mathrm{P}^{+}$core from the vacuum and counter charges. The surface is highly dominated by the hydrocarbon chains.

Following recent reports of their successful preparation and extensive characterization involving various physicochemical properties, ${ }^{6,7}$ this current study provides a fundamental view of the surface molecular structure of these liquid salts through a nonlinear, surface-sensitive, vibrational spectroscopic technique, sum frequency generation (SFG) spectroscopy. The compounds studied (see Fig. 1) include a series of six alkyltrioctylphosphonium chlorides, in which the fourth alkyl chain is systematically varied from $n=4$, $5,8,10,12$, or 14 and is referred to as the "fourth alkyl chain" throughout this manuscript. Tetraoctylphosphonium chloride, $\left[\mathrm{P}_{8} 8_{8} 8_{8}\right][\mathrm{Cl}]$, represents the symmetrical cation in the sequence, while methyl(diethyl)butylphosphonium bis(trifluoromethyl)sulfonyl) amide, [ $\left.\begin{array}{llll}\mathrm{P}_{1} & 2 & 4\end{array}\right]\left[\mathrm{NTf}_{2}\right]$, represents the lowest symmetry compared to all other cations in the series. For chloride ionic liquids, the results of the simulation on orientational behavior of the $-\mathrm{CH}_{3}$ terminal group protruding to the vapor is used to explain 

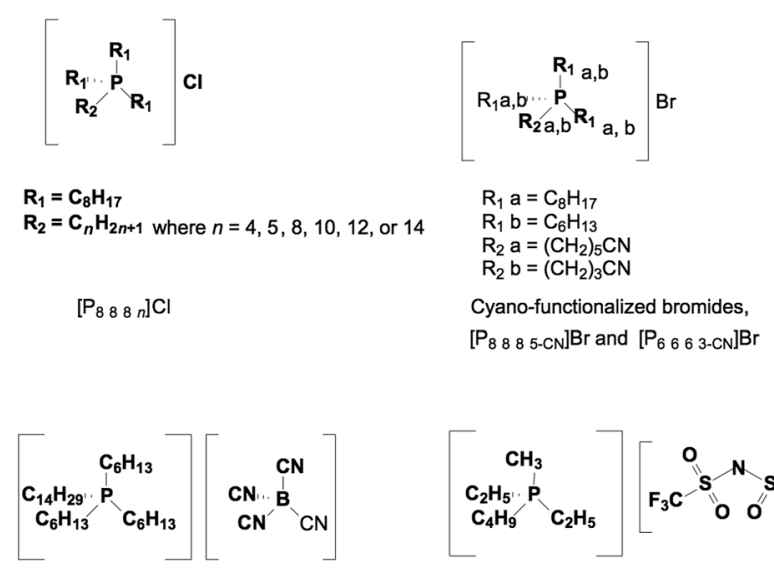

$\left[\mathrm{P}_{6} 666\right.$ 14][B(CN) $]$

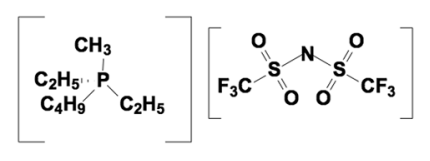

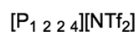

FIG. 1. Structures of the ionic liquids investigated, which include a series of six different alkyltrioctylphosphonium chlorides, trioctyl(5cyanopentyl)phosphonium bromide, trihexyl(3-cyanopropyl)phosphonium bromide, tetradecyl(trihexyl)phosphonium tetracyanoborate, and methyl(diethyl)butylphosphonium bis $\{$ (trifluoromethyl)sulfonyl) $\}$ amide.

the appearance and changes in the SFG spectral peaks as the "4th" alkyl chain length increases from $n=8$ to 14 . Moreover, this work also investigates the cyano-containing ionic liquids, trioctyl(5-cyanopentyl)phosphonium bromide ([ $\mathrm{P}_{8} 8$ 8 8 5-CN $\left.] \mathrm{Br}\right)$, trihexyl(3-cyanopropyl)phosphonium bromide $\left(\left[\mathrm{P}_{6} 663_{-}-\mathrm{CN}\right] \mathrm{Br}\right)$, and tetradecyl(trihexyl)phosphonium tetracyanoborate $\left(\left[\mathrm{P}_{6} 66_{14}\right]\left[\mathrm{B}\left(\mathrm{CN}_{4}\right)\right]\right)$. The ionic liquids chosen in this study are meant to elucidate the roles of 1 . cation chain length, 2. anion, 3. cation symmetry, and 4. configuration of chains at the interface.

In order to assign the vibrational resonances observed

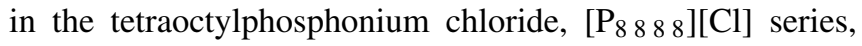
three ionic liquids were further prepared and characterized, specifically tetrabutylphosphonium chloride, $\left[\mathrm{P}_{4444}\right][\mathrm{Cl}]$, tributyl(4-methoxybutyl)phosphonium chloride, $\left[\mathrm{P}_{4} 44\right.$ 4-OMe $]$ $[\mathrm{Cl}]$, and trioctyl(2-methoxyethyl)phosphonium chloride, $\left[\mathrm{P}_{8} 88\right.$ 2-OMe $][\mathrm{Cl}]$. The "4th" chain in $\left[\mathrm{P}_{4444}\right][\mathrm{Cl}]$ is longer than the three base (-tributyl) chains; while in $\left[\mathrm{P}_{8} 8\right.$ 8 2 2-OMe $][\mathrm{Cl}]$, the "4th" chain is shorter than the three base (-trioctyl) chains. The structures are shown in Fig. 2.

The progression and variation in the sequence of ionic liquids involved in this report allows for the examination of the crucial role that the structure, type, and shape of the cation (and, to a minor degree, the anion) play in the overall surface molecular structure of the liquid salt. This is highly critical to the fundamental understanding of the surface chemistry of phosphonium ionic liquids, which guides further interpretation of physicochemical surface properties relevant to industrial use.

\section{Sum frequency generation (SFG) spectroscopy}

$\mathrm{SFG}$ is a second-order nonlinear spectroscopic technique which selectively detects surface molecules (present in a noncentrosymmetric environment) with a preferential ordering compared to the isotropic bulk. Therefore, the technique is inherently used as a tool in the study of interfaces (i.e., twophase systems) in which the symmetry is broken. Several
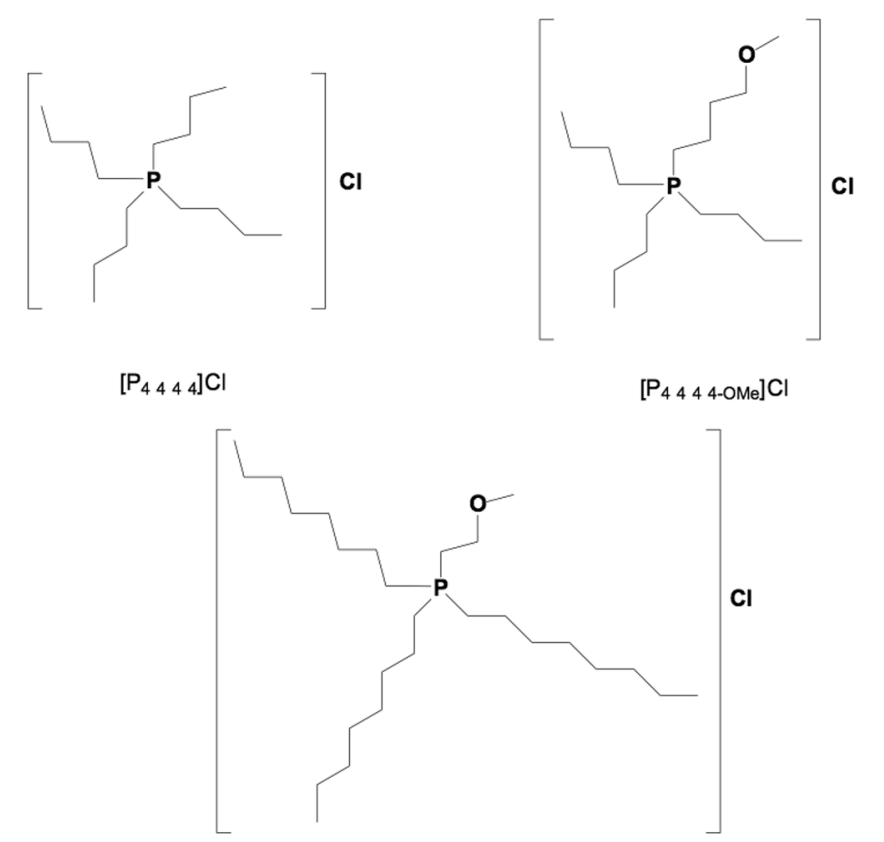

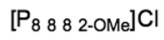

FIG. 2. Structures of ionic liquids: tetrabutylphosphonium chloride $\left[\mathrm{P}_{4444}\right][\mathrm{Cl}]$, tributyl(4-methoxybutyl)phosphonium chloride $\left[\mathrm{P}_{4444-\mathrm{OMe}}\right][\mathrm{Cl}]$, and trioctyl(2-methoxyethyl)phosphonium chloride $\left[\mathrm{P}_{8} 88\right.$ 8 $\left.2-\mathrm{OMe}\right][\mathrm{Cl}]$.

publications discuss the theory behind SFG and can be readily found in the literature. ${ }^{28-31}$

Experimentally, SFG used here involves two pulsed laser beams: a 532-nm fixed visible and tunable IR (2000$4000 \mathrm{~cm}^{-1}$ ) overlapped on the surface to generate a sum frequency beam, so-called because it has a frequency equivalent to the sum of the two incident beams. The electric fields associated with the high-intensity input beams $\left(E_{\mathrm{IR}}, E_{\mathrm{vis}}\right)$ result in a second order nonlinear polarization, $P^{(2)}$, on the surface. The second-order nonlinear susceptibility tensor, $\chi^{(2)}$, relates the induced polarization response to the electric fields. Equation (1) shows the intensity of the sum frequency beam, $I\left(\omega_{\mathrm{SF}}\right)$, which is proportional to the square of the induced polarization $P^{(2)}$ as described by

$$
I\left(\omega_{S F}\right) \propto\left|P^{(2)}=\chi^{(2)}: E_{v i s} E_{I R}\right|^{2} .
$$

$\chi^{(2)}$ is a function of the infrared wavenumber and contains vibrational information on the molecular response to the optical fields. $\chi_{\mathrm{R}}$ is composed of the orientationally averaged microscopic contributions, $\beta$, as seen in the following equation:

$$
\chi^{(2)}=N\langle\beta\rangle \text {. }
$$

The hyperpolarizability, $\beta$, represents the average of all possible molecular orientations. This term also contains the Raman polarizability and the IR dipole transition of the molecular system. The terms $\omega_{I \mathrm{R}}, \omega_{\mathrm{q}}$, and $\Gamma_{\mathrm{q}}$ denote the frequency of the IR beam, frequency of the normal mode, and the damping constant of the $q$ th vibrational mode, respectively, while $N$ is the number of molecular modes contributing to the vibration. From Eq. (1) it is clear that the intensity of the SFG signal 
is directly related to the magnitude of $\chi^{(2)}$. In Eq. (3), the expression for the resonant term, $\chi_{\mathrm{R}}^{(2)}$, is shown, suggesting that when the infrared frequency $\left(\omega_{I R}\right)$ matches the frequency of a vibrational mode $\left(\omega_{q}\right)$ of the interfacial molecules, $\omega_{I R}-\omega_{q}$ is equal to 0 and the magnitude of $\chi^{(2)}$ is significantly enhanced, resulting in an increase in the SFG signal. The amplitude of the mode, A, is proportional to $\chi^{(2)}$,

$$
\chi_{R}^{(2)}=\sum\left[\frac{A}{\omega_{I R}-\omega_{q}+i \Gamma_{q}}\right] .
$$

Plotting the SF light detected as a function of IR frequency results in a vibrational spectrum. Note that $\chi^{(2)}$ has a magnitude that depends on the polar orientation of the molecule on the surface. Finally, since SFG is nonlinear and coherent spectroscopy, the various Cartesian components of the susceptibility tensor, $\chi^{(2)}$, are probed by varying the polarizations of the incident and output beams, from which the molecular orientation with respect to the surface normal can be measured. ${ }^{29,32,33}$

\section{EXPERIMENTAL METHOD}

\section{Samples}

All phosphonium ionic liquids were synthesized and fully

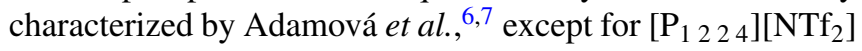
and $\left[\mathrm{P}_{6661_{14}}\right]\left[\mathrm{B}(\mathrm{CN})_{4}\right]$, which were provided by Cytec Industries (Canada) and Merck, respectively. Ionic liquids $\left[\mathrm{P}_{4444}\right][\mathrm{Cl}],{ }^{6}\left[\mathrm{P}_{4444-\mathrm{OMe}}\right][\mathrm{Cl}]$, and $\left[\mathrm{P}_{8} 88\right.$ C2-OMe $]$ were synthesized at the Queen's University Ionic Liquid Laboratories (QUILL). Detailed characterization included NMR spectroscopy $\left({ }^{1} \mathrm{H},{ }^{13} \mathrm{C}\right.$, and $\left.{ }^{31} \mathrm{P} \mathrm{NMR}\right)$; mass spectrometry; elemental carbon and hydrogen content; halide and water contents; differential scanning calorimetry (DSC); thermogravimetric analysis (TGA); density; and viscosity measurements. ${ }^{6,7}$ Moreover, molar volumes as a function of temperature were estimated via a group contribution method as well as thermal expansion coefficients calculated from density data. ${ }^{6,7}$ A brief summary of synthetic details is provided below. The synthesis of $\left[\begin{array}{llll}\mathrm{P}_{8} & 8 & 4\end{array}\right][\mathrm{Cl}]$ involved chloroalkanes of mid-range volatility, requiring the use of a microwave reactor, while thermal reflux was employed for all remaining alkyltrioctylphosphonium chloride samples. ${ }^{7}$ The salts $\left[\mathrm{P}_{4444}\right][\mathrm{Cl}],\left[\mathrm{P}_{8} 88_{2}\right.$-OMe $][\mathrm{Cl}]$, and $\left[\mathrm{P}_{4444-\mathrm{OMe}}\right][\mathrm{Cl}]$ were prepared by nucleophilic $\left(\mathrm{S}_{\mathrm{N}} 2\right)$ addition of tributylphosphine to the appropriate chlorinated alkylating agent. As both the tributylphosphine and trioctylphosphine were supplied in 50\% (v/v) toluene solution (in order to reduce flammability), the solvent was removed when the reaction was complete. The toluene decreased the reaction rate. Synthetic procedure details are presented in the supplementary material.

\section{Sample preparation prior to SFG measurements}

Fully characterized sealed samples were sent directly from the QUILL Research Centre in Belfast and similar preparation procedures for spectroscopic measurements were followed as described in an earlier publication. ${ }^{34} \mathrm{~A}$ custom-designed SFG cell $^{35}$ made of Pyrex® glass, equipped with high-vacuum valves and O-ring fittings, was used to contain all ionic liquid samples. Samples were introduced directly into the SFG vessel and dried in a glass vacuum line equipped with an ionization gauge for measuring pressure, a turbo-molecular pump backed by a mechanical pump, and liquid nitrogen traps. Kalrez ${ }^{\circledR}$ O-rings were utilized as well as Teflon ${ }^{\circledR}$ stopcocks to ensure non-reactivity of samples with materials used for vacuum sealing. Samples were dried until a desired pressure of $\leq 5 \times 10^{-5}$ Torr was reached with occasional heating $\left(\leq 60{ }^{\circ} \mathrm{C}\right)$ with a heat gun to hasten the drying process. The samples were known to be thermally stable at the heating temperature used.

Specifically for $\left[\mathrm{P}_{12} 2_{2}\right]\left[\mathrm{NTf}_{2}\right]$, a more constant heating at less than $60^{\circ} \mathrm{C}$ using an insulated heating tape was required, as the sample tended to solidify at room temperature when it was directly in contact with atmospheric moisture. When sufficiently dry, however, $\left[\mathrm{P}_{12} 2_{4}\right]\left[\mathrm{NTf}_{2}\right]$ remained liquid at room temperature. Moreover, $\left[\mathrm{P}_{4444}\right][\mathrm{Cl}]$ has a melting point between 62 and $66{ }^{\circ} \mathrm{C}$ such that drying in the vacuum line was done with heating above the melting temperature and all SFG measurements were done at $\sim 70{ }^{\circ} \mathrm{C}$. Once the desired pressure was reached, the SFG cell containing samples while attached to the vacuum line was back-filled with ultra-high purity nitrogen gas to a slight overpressure. SFG measurements then followed. For $\left[\mathrm{P}_{8} 88\right.$ 2-OMe $][\mathrm{Cl}]$, temperature-dependent data were recorded in addition to room-temperature measurements: this sample was initially dried in the glass vacuum line prior to external cooling (to $0{ }^{\circ} \mathrm{C}$ using an ice bath) and heating (up to $50{ }^{\circ} \mathrm{C}$ using a Variac $($-controlled heating tape).

\section{SFG spectroscopy system}

The SFG spectrometer setup has been described in earlier publications. ${ }^{34,36,37}$ A fundamental 1064-nm output beam from a picosecond pulsed Nd:YAG (EKSPLA) was used to pump an optical parametric generator/amplifier (OPG/OPA, LaserVision) system. From the OPG/OPA system, a fixed visible (532-nm) and a frequency tunable IR $\left(2000-4000 \mathrm{~cm}^{-1}\right)$ beam were generated. Using a co-propagating geometry, the two beams were overlapped at the liquid surface at an angle of $50^{\circ}$ (visible) or $60^{\circ}$ (IR) from the surface normal. The resulting SFG signal was then collected using a gated integrator and controlled using the LabVIEW software.

\section{Data collection and analysis}

Data were collected at an average of 5 scans per polarization combination. A scan rate of $1 \mathrm{~cm}^{-1} \mathrm{~s}^{-1}$ using 20 laser shots per point was used. The SFG signal from a clean gold substrate was taken before any sample measurement, which was used to normalize each spectrum to correct for deviations (i.e., absorption by the bulk and the fluctuations in the IR beam due to the changing efficiency of the OPG/OPA system). To calibrate the tunable IR wavenumber, spectra from a $0.038 \mathrm{~mm}$ thick polystyrene film were used as reference. Moreover, to make a reliable comparison of spectra between samples, the SFG intensity of each spectrum was 
normalized against the intensity of the $\mathrm{CH}_{3}$ symmetric stretch peak in ssp ( $s$-polarized SFG beam, $s$-polarized visible beam, and $p$-polarized IR beam) of a standard solution of hexadecanol in water. Finally, spectra were fitted using the Origin 7.0 Professional nonlinear curve fitting software, using Eq. (3) as a fitting function. Four different polarization combinations were taken for all ionic liquid samples, namely, ssp, ppp, sps, and pss.

\section{Molecular dynamics simulation}

Details of cation-anion and cation-cation structures in the surface region of $\left[\mathrm{P}_{8} 8_{8}{ }_{n}\right][\mathrm{Cl}]$ (where $n=8,10$, or 12) ionic liquids, using atomistic classical molecular dynamics (MD) simulation, are presented to support the SFG spectral observations. The simulation details and procedures are provided in the supplementary material.

A single ion-pair of each ionic liquid, optimized via the density functional theory (DFT) calculation, ${ }^{38}$ was replicated to obtain a large-size cubic simulation box (Table S1 of the supplementary material) containing 1200 ion-pairs of each ionic liquid (122 400, 122 960, and 136800 atoms). All alkyl chains were in their most stable (all-trans, gauche-free) con-

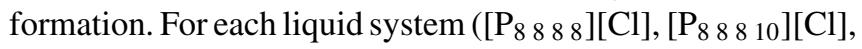
and $\left.\left[\mathrm{P}_{8} \quad 8 \quad 8{ }_{12}\right][\mathrm{Cl}]\right)$, simulation studies of the liquid/vacuum interface were performed at $400 \mathrm{~K}$ and ambient pressure using Gromacs ${ }^{39}$ package (4.5.5) with the Optimized Potential for Liquid Simulation All-Atom (OPLS-AA) ${ }^{40}$ force field. After the 25-ns simulation, the final ensemble consisted of a slab of ionic liquids with a thickness of $\sim 129.5-143.5$

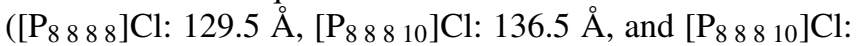
$143.5 \AA$ ) equilibrated at the middle of box, and the surface normal extended in the $Z$-direction to $350 \AA$. The infrequent inhomogeneity of these ion-pair liquid systems with large cation and strong $\mathrm{P}-\mathrm{Cl}$ interaction ${ }^{41}$ is of special concern for a reliable simulation of the surface. Simulations at high temperature ( $400 \mathrm{~K}$ and ambient pressure) ensure that the slow dynamics of these ionic liquids do not lead to artificial results (SFG spectra at $0{ }^{\circ} \mathrm{C}$ and $50{ }^{\circ} \mathrm{C}$ are indistinguishable; see Fig. S3 of the supplementary material). The simulation results were analyzed for the anion-cation relation, and the trend of structure and orientation of cation in the surface region was determined as a function of the alkyl chain length.

\section{RESULTS AND DISCUSSION}

\section{Alkyltrioctylphosphonium chloride series}

The sum frequency spectra in the $\mathrm{C}-\mathrm{H}$ stretching region of $2750-3100 \mathrm{~cm}^{-1}$ taken at four different polarization combinations for all alkyltrioctylphosphonium chlorides,

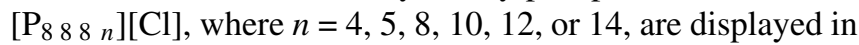
Fig. 3, offset in the same plot.

The variation in this select series of samples allows for determining characteristic changes in the vibrational bands; this is seen as the number of carbon atoms in the fourth alkyl substituent is increased or decreased from the perspective of

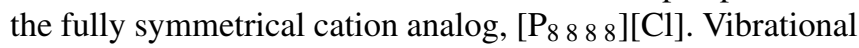
mode assignments used are based on results from a series of tetraalkylammonium and 1,1-dialkylpyrrolidinium ionic liquids previously discussed ${ }^{35}$ and summarized in Table I. Peaks for all vibrational modes observed in this study are summarized in Table II.
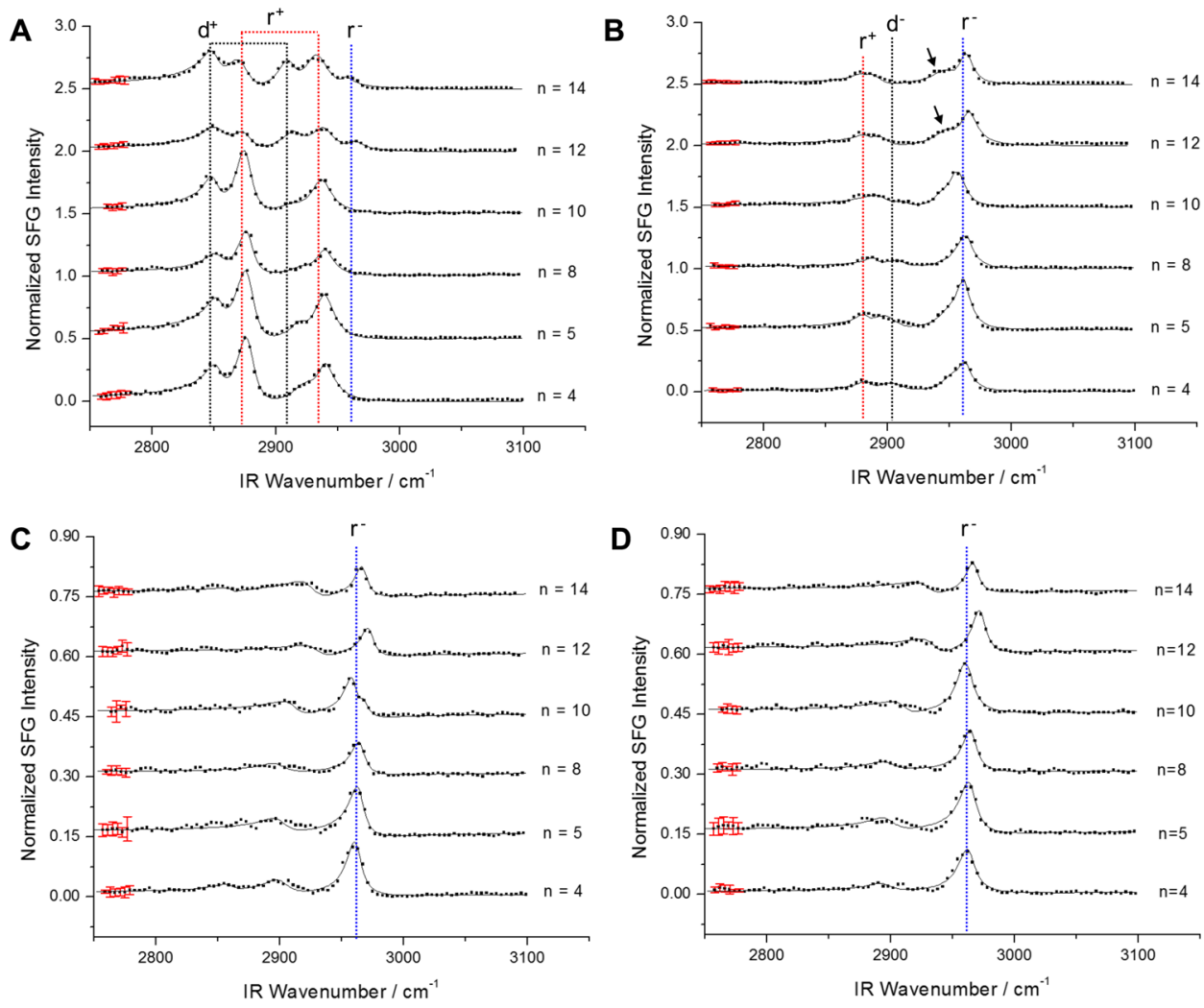

FIG. 3. Sum frequency spectra of alkyltrioctylphosphonium chlorides, $\left[\mathrm{P}_{8} 88_{8} n\right][\mathrm{Cl}]$ (where $n=4,5,8,10,12$, or 14), at polarization combinations (a) $s s p$, (b) ppp, (c) sps, and (d) pss. The offsets are $0.50,0.50,0.15$, and 0.15 , respectively. Arrow points to the peak emerging at $\sim 2950 \mathrm{~cm}^{-1}$ due the split in the $\mathrm{r}^{-}$mode in ppp. 
TABLE I. Vibrational assignments for tetraalkylammonium and 1,1dialkylpyrrolidinium ionic liquids used to define spectra of the tetraalkylphosphonium ionic liquids. ${ }^{42}$

\begin{tabular}{lc}
\hline \hline \multicolumn{1}{c}{ Vibrational mode } & Wavenumber $/ \mathrm{cm}^{-1}$ \\
\hline Asymmetric methyl stretch, $\mathrm{r}^{-}$ & $2960-2970$ \\
Methyl Fermi resonance, $\mathrm{r}^{+}$FR & $2931-2942$ \\
Methylene Fermi resonance, $\mathrm{d}^{+}$FR & $\sim 2920$ \\
Asymmetric methylene stretch, $\mathrm{d}^{-}$ & $\sim 2910$ \\
Symmetric methyl stretch, $\mathrm{r}^{+}$ & $2870-2880$ \\
Symmetric methylene stretch, $\mathrm{d}^{+}$ & $2845-2858$ \\
\hline \hline
\end{tabular}

In $s s p$ polarization, the spectra show vibrations corresponding to $\mathrm{d}^{+}, \mathrm{r}^{+}, \mathrm{d}^{+} \mathrm{FR}$, and $\mathrm{r}^{+}{ }_{\mathrm{FR}}$ modes. An additional mode observed in the spectra which is assigned to the $\mathrm{r}^{-}$mode, while absent for the series with $n=4,5,8$, or 10 , is visible for the last two alkyltrioctylphosphonium chlorides with $n=12$ and 14. Moreover, for $n=4,5,8$, and 10, the $\mathrm{r}^{+}$mode is the most intense band, while for $n=12$ and 14, an obvious switch in the intensity of the bands occurs such that the $\mathrm{d}^{+}$ mode becomes more intense than the $\mathrm{r}^{+}$mode. Along with this switch is the appearance of the $\mathrm{r}^{-}$mode and prominent signal enhancement of the $\mathrm{d}^{+} \mathrm{FR}$ mode, whereas for members in the series with alkyl chains up to $n=10$, the peak occurs as a mere shoulder.

In $p p p$ polarization, the spectra are dominated by the $\mathrm{r}^{-}$ mode, being the most intense band. Fundamental and Fermi resonance modes for the $\mathrm{r}^{+}$and $\mathrm{d}^{+}$are of relatively weak intensity and are barely visible (see Table II). However, fitting results for $n=4,5$, or 8 reveal weak modes which may be assigned to the $\mathrm{d}^{-}$mode rather than the $\mathrm{d}^{+}{ }_{\mathrm{FR}}$, as the fundamental, $\mathrm{d}^{+}$, appears too weak. In particular, the symmetrical $\left[\begin{array}{llll}\mathrm{P}_{8} & 8 & 8 & 8\end{array}\right][\mathrm{Cl}]$ has bands assigned to the $\mathrm{r}^{+}$and $\mathrm{d}^{-}$occurring as a well-defined split as opposed to a broad band. Finally, for $n=12$ or 14 , the split in the $\mathrm{r}^{-}$mode in ppp clearly appears [indicated by the arrows in Fig. 3(b)]; whereas in all others in the series, this feature is absent. Also, this $\mathrm{r}^{-}$mode is only apparent in these two ionic liquids with $n=12$ or 14 in the $s s p$ combination.

The pss and sps spectra likewise show the $\mathrm{r}^{-}$mode as the most intense peak as well as a weak contribution from the $\mathrm{d}^{-}$ peak. For $\left[\mathrm{P}_{8} 88_{10}\right][\mathrm{Cl}]$ in the sps, a residual peak at $2968 \mathrm{~cm}^{-1}$ is additionally observed, which is due to the $\mathrm{r}^{-}$mode split differentiating the in-plane vs. out-of-plane vibrations. For $n=12$ or 14 , a consistent shift in frequency for the $\mathrm{r}^{-}$mode was also obvious in both sps and pss spectra.

\section{Tetraalkylphosphonium salts with other anions}

Figure 4 displays the sum frequency spectra of $\left[\mathrm{P}_{8} 88\right.$ 5-CN $][\mathrm{Br}], \quad\left[\mathrm{P}_{6} 663_{3}-\mathrm{CN}\right][\mathrm{Br}], \quad\left[\mathrm{P}_{12} 24\right]\left[\mathrm{NTf}_{2}\right], \quad$ and $\left[\mathrm{P}_{6} 66_{14}\right]\left[\mathrm{B}(\mathrm{CN})_{4}\right]$ at $s s p$ polarization offset in the same plot (ppp, sps, and pss are shown in Fig. S3 of the supplementary material). From this set, changes were expected in the spectral profile as a cyano-group is added to the cation moiety, and due to the substitution of the chloride or bromide anions with more bulky constituents such as bis $\{$ (trifluoromethyl)sulfonyl) $\}$ amide, $\left[\mathrm{NTf}_{2}\right]^{-}$, and tetracyanoborate $\left[\mathrm{B}(\mathrm{CN})_{4}\right]^{-}$. Particularly interesting, here, is the addition of the highly unsymmetrical $\left[\begin{array}{lll}\mathrm{P}_{1} & 2 & 2\end{array}\right]\left[\mathrm{NTf}_{2}\right]$ to the series. Table III summarizes the peak assignments for this particular set.

\section{$\left[\mathrm{P}_{8} 88\right.$ 5-CN] $[\mathrm{Br}]$ and $\left[\mathrm{P}_{6} 666\right.$ 3-CN] $[\mathrm{Br}]$}

The ssp spectra (Fig. 4) for both compounds appear very similar to that of the $\left[\mathrm{P}_{8} 8_{8}{ }_{n}{ }_{n}\right][\mathrm{Cl}]$ series, where $n=4,5,8$, or 10 , such that $\mathrm{d}^{+}, \mathrm{r}^{+}, \mathrm{d}^{+} \mathrm{FR}$, and $\mathrm{r}^{+} \mathrm{FR}$ modes dominate the spectra. The $\mathrm{r}^{+}$mode is found to be the most intense just as in the $\left[\begin{array}{llll}\mathrm{P}_{8} & 8 & { }_{n} & n\end{array}\right][\mathrm{Cl}]$ series for up to $n=10$. This shows that variation of the fourth alkyl chain by the addition of a cyano-functional group has little or no effect on the average orientation of the cation chain contributing to the observed vibrational frequency. (Note the similar ionic radii of the anions, $\mathrm{Br}^{-}$and $\mathrm{Cl}^{-}$.) For the ppp combination (Fig. S3 of the supplementary material), the vibrational modes appear similar as well when compared to the alkyltrioctylphosphonium chlorides, except for the appearance of two different vibrational modes. All three modes, namely, the $\mathrm{r}^{+}, \mathrm{d}^{-}$, and $\mathrm{r}^{-}$modes are present in both ionic liquids; however, the $\mathrm{r}^{-}{ }_{i p}$ mode split at $2954 \mathrm{~cm}^{-1}$ is only observed for $\left[\mathrm{P}_{6} 663_{-}-\mathrm{CN}\right] \mathrm{Br}$. On the other hand, the $\mathrm{d}^{+} \mathrm{FR}$ mode at $2910 \mathrm{~cm}^{-1}$, which is absent in $\left[\mathrm{P}_{6} 663_{-\mathrm{CN}}\right] \mathrm{Br}$, is observed in $\left[\mathrm{P}_{8} 8\right.$ 8 5-CN $] \mathrm{Br}$. Finally, the sps and pss spectra for both ionic liquids appear similarly dominated by the weak $\mathrm{d}^{-}$mode and more intense $\mathrm{r}^{-}$mode. These two ionic liquids illustrate the effect of removing the methyl group contributions to the SFG spectrum on the dissimilar fourth-chain. The results suggest that the three identical chains contribute significantly to the overall SFG signal.

TABLE II. Vibrational modes observed for alkyltrioctylphosphonium chloride ionic liquids.

\begin{tabular}{|c|c|c|c|c|c|c|c|c|c|c|c|c|}
\hline \multirow[b]{3}{*}{ 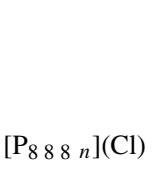 } & \multicolumn{12}{|c|}{ Peak assignment (wavenumber/ $\mathrm{cm}^{-1}$ ) } \\
\hline & \multirow{2}{*}{$\begin{array}{l}\mathrm{d}^{+} \\
s s p\end{array}$} & \multicolumn{2}{|c|}{$\mathrm{r}^{+}$} & \multicolumn{2}{|c|}{$\mathrm{d}^{-}$} & \multicolumn{2}{|c|}{$\mathrm{d}^{+} \mathrm{FR}$} & \multirow{2}{*}{$\begin{array}{c}\mathrm{r}^{+}{ }_{\mathrm{FR}} \\
s s p\end{array}$} & \multicolumn{4}{|c|}{$\mathrm{r}^{-}$} \\
\hline & & $s s p$ & ppp & ppp & sps & $s s p$ & ppp & & $s s p$ & $p p p_{i p}$ & ppp $_{o p}$ & sps \\
\hline$n=4$ & 2853 & 2877 & 2884 & 2906 & 2901 & 2924 & $\ldots$ & 2940 & $\ldots$ & $\ldots$ & 2962 & 2961 \\
\hline 5 & 2854 & 2877 & 2882 & 2900 & 2901 & 2920 & $\ldots$ & 2939 & $\ldots$ & $\ldots$ & 2962 & 2964 \\
\hline 8 & 2855 & 2879 & 2890 & 2909 & 2899 & 2923 & $\ldots$ & 2942 & $\ldots$ & $\ldots$ & 2963 & 2965 \\
\hline 10 & 2851 & 2876 & 2898 & $\ldots$ & 2911 & 2913 & 2917 & 2937 & $\ldots$ & $\ldots$ & 2959 & 2959 \\
\hline 12 & 2854 & 2875 & 2883 & $\ldots$ & 2930 & 2915 & 2897 & 2938 & 2963 & 2950 & 2965 & 2972 \\
\hline 14 & 2851 & 2872 & 2879 & $\ldots$ & 2925 & 2910 & 2890 & 2932 & 2955 & 2948 & 2963 & 2967 \\
\hline
\end{tabular}




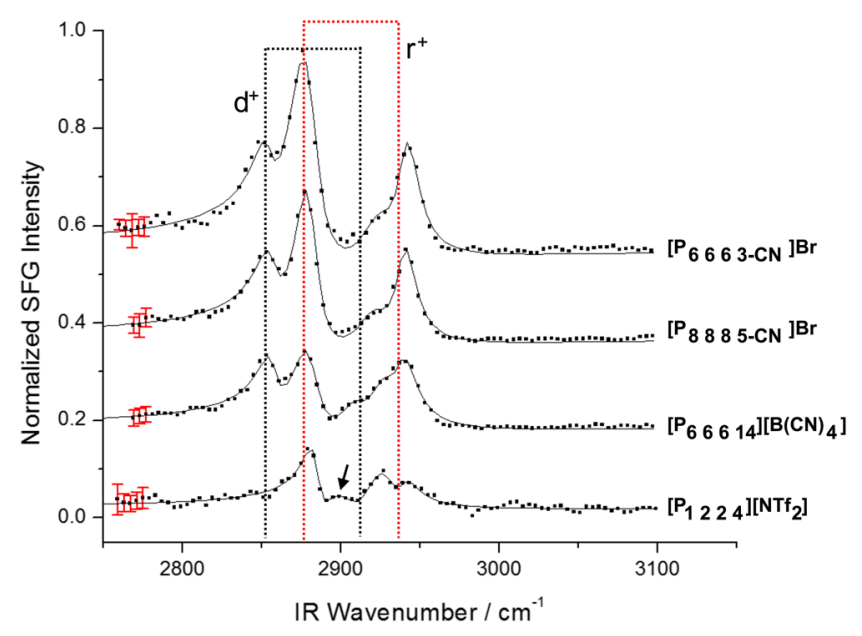

FIG. 4. Sum frequency spectra of tetraalkylphosphonium ionic liquids with various anions at polarization combination ssp offset at 0.18 . The arrow points to the $\mathrm{r}^{+}$mode at $\sim 2901 \mathrm{~cm}^{-1}$ which is due to the terminal methyl group.

\section{$\left[P_{12} 24\right]\left[\mathrm{NTf}_{2}\right]$}

Four distinct peaks are visible in the $s s p$ spectrum (Fig. 4) for this highly unsymmetrical analog. The peak at $2884 \mathrm{~cm}^{-1}$ assigned to the $\mathrm{r}^{+} / \mathrm{r}^{+} \mathrm{FR}$ mode contains contributions from both butyl and ethyl groups attached to the cation (Table III). The peak at $2901 \mathrm{~cm}^{-1}$, which is also an $\mathrm{r}^{+}$mode, is characteristic for the vibration of the terminal methyl attached to phosphorus (as in trimethylphosphine). ${ }^{43}$ The peak at $2925 \mathrm{~cm}^{-1}$ is assigned to the $\mathrm{r}^{+}$mode from the ethyl chains, while the peak at $2940 \mathrm{~cm}^{-1}$ is from the $\mathrm{r}_{\mathrm{FR}}^{+}$of the butyl chain. ${ }^{29,44,45}$ For the ppp spectra (Fig. S3 of the supplementary material), the $\mathrm{d}^{-}$mode appears within the noise level, while the $\mathrm{r}^{-}$mode which dominates the spectra is split into two modes, $-\mathrm{r}^{-} i p$ and $\mathrm{r}^{-}{ }_{o p}$, respectively. For sps and pss spectra (Fig. S3 of the supplementary material), the $\mathrm{r}^{-}$mode is the most intense, but the $\mathrm{d}^{-}$mode at $2918 \mathrm{~cm}^{-1}$ is only observed in the sps combination. The $\mathrm{r}^{-}$mode also appears to be shifted to higher frequency in both combinations. Consequently, an additional shoulder at $2990 \mathrm{~cm}^{-1}$ absent in the sps spectra is observed in the pss combination. Thus even the shortest alkyl chain (i.e., methyl) contributes to the surface spectrum and appears to have a significant orientation.

\section{$\left[\mathrm{P}_{666614}\right]\left[\mathrm{B}(\mathrm{CN})_{4}\right]$}

The $s s p$ spectra show five peaks corresponding to four distinct modes (Table III). The peak at $2858 \mathrm{~cm}^{-1}$ corresponds to the $\mathrm{d}^{+}$mode, while the peak at $2880 \mathrm{~cm}^{-1}$ corresponds to the $\mathrm{r}^{+}$mode. Two peaks at 2909 and $2927 \mathrm{~cm}^{-1}$ are both assigned to one vibrational mode, ${ }^{46} \mathrm{~d}^{+}$FR. The peak at $2939 \mathrm{~cm}^{-1}$ in the $s s p$ pertains to the $\mathrm{r}_{\mathrm{FR}}^{+}$mode. Both peaks at 2909 and $2927 \mathrm{~cm}^{-1}$ are also visible in the $p p p$ spectra (Fig. S3 of the supplementary material). In addition, the $\mathrm{r}^{-}$ip mode at $2945 \mathrm{~cm}^{-1}$ and the $\mathrm{r}^{-}{ }_{o p}$ mode at $2966 \mathrm{~cm}^{-1}$ are observed. Like all others in the

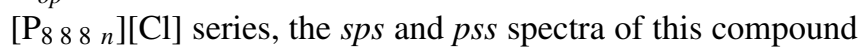
are dominated by a weak $\mathrm{d}^{-}$mode and a much more intense $\mathrm{r}^{-}$mode (Fig. S5 of the supplementary material). Interestingly

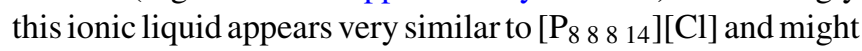
indicate the minor influence of the anions to the surface of the ionic liquid with large alkylphosphonium cations. Figure S6 of the supplementary material shows a top view snapshot of the MD simulation. Results show that the simulated slab of ionic liquids has alkyl groups which protrude to the vapor phase, as shown in Fig. S7 of the supplementary material.

\section{Tetraalkylphosphonium chlorides containing methoxy-groups}

Figure 5 displays ssp SFG spectra of tetraalkylphosphonium chlorides in which one of the four alkyl substituents attached to phosphorus contains a methoxy group, as in 2-methoxyethyl $\left(-\mathrm{C}_{2} \mathrm{H}_{4}-\mathrm{OMe}\right)$ or 4-methoxybutyl $\left(-\mathrm{C}_{4} \mathrm{H}_{8}-\right.$ $\mathrm{OMe}$ ). To emphasize the effect introduced by adding a heteroatom (methoxy) group to the alkyl structure, spectra are overlaid and compared to their corresponding tetraalkylphosphonium chloride analog. Thus, Fig. 5(a) shows overlaid spectra for $\left[\mathrm{P}_{4444}\right][\mathrm{Cl}]$ and $\left[\mathrm{P}_{4444-\mathrm{OMe}}\right][\mathrm{Cl}]$, while Fig. 5(b) shows those for $\left[\mathrm{P}_{8} 88\right.$ 2-OMe $][\mathrm{Cl}]$ and $\left[\mathrm{P}_{8} 884\right][\mathrm{Cl}]$. Spectra are offset on the same plot in both figures with differences which are discussed in the following sections below.

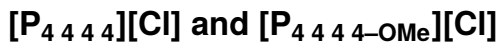

SFG spectra for the fully symmetrical $\left[\mathrm{P}_{4444}\right][\mathrm{Cl}]$, illustrated in Fig. 5, show two peaks in $s s p$, at $2880 \mathrm{~cm}^{-1}$ assigned to the $\mathrm{r}^{+}$mode and at $2943 \mathrm{~cm}^{-1}$ assigned to the $\mathrm{r}^{+} \mathrm{FR}$ mode. Additional peaks were observed for $\left[\mathrm{P}_{4444-\mathrm{OMe}}\right][\mathrm{Cl}]$ in $s s p$, assigned to the $-\mathrm{OCH}_{3}$ symmetric mode at $2815 \mathrm{~cm}^{-1}$, the

TABLE III. Vibrational modes observed for tetraalkylphosphonium ionic liquids with various anions.

\begin{tabular}{|c|c|c|c|c|c|c|c|c|c|c|c|c|}
\hline \multirow{3}{*}{$\begin{array}{l}\text { Ionic } \\
\text { liquid }\end{array}$} & \multicolumn{12}{|c|}{ Peak assignment (wavenumber/ $\mathrm{cm}^{-1}$ ) } \\
\hline & \multirow{2}{*}{$\begin{array}{l}\mathrm{d}^{+} \\
s s p\end{array}$} & \multicolumn{2}{|l|}{$\mathrm{r}^{+}$} & \multicolumn{2}{|c|}{$\mathrm{d}^{-}$} & \multicolumn{2}{|c|}{$\mathrm{d}^{+} \mathrm{FR}$} & \multirow{2}{*}{$\begin{array}{c}\mathrm{r}^{+} \mathrm{FR} \\
s s p\end{array}$} & \multicolumn{4}{|c|}{$\mathrm{r}^{-}$} \\
\hline & & $s s p$ & ppp & ppp & sps & $s s p$ & ppp & & $s s p$ & $p p p_{i p}$ & $\operatorname{ppp}_{o p}$ & sps \\
\hline$\left[\mathrm{P}_{6} 6663-\mathrm{CN}\right][\mathrm{Br}]$ & 2855 & 2879 & 2883 & 2903 & 2892 & 2925 & $\ldots$ & 2942 & $\ldots$ & 2954 & 2966 & 2969 \\
\hline$\left[\mathrm{P}_{8} 88_{5-} 5_{-} \mathrm{CN}\right] \mathrm{Br}$ & 2857 & 2880 & 2886 & 2896 & 2901 & 2922 & 2910 & 2940 & $\ldots$ & - & 2964 & 2965 \\
\hline 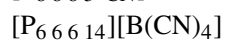 & 2858 & 2880 & $\ldots$ & $\ldots$ & 2920 & $\{2909\}\{2927\}$ & $\{2909\}\{2927\}$ & 2939 & $\ldots$ & 2945 & 2966 & 2968 \\
\hline$\left[\begin{array}{lll}\mathrm{P}_{1} & 2 & 2\end{array}\right]\left[\mathrm{NTf}_{2}\right]$ & $\ldots$ & $2925^{\mathrm{a}} 2901^{\mathrm{b}}$ & $\ldots$ & 2900 & 2901 & $\ldots$ & $\ldots$ & $2884^{\mathrm{c}} 2940^{\mathrm{d}}$ & $\ldots$ & 2954 & 2973 & 2965 \\
\hline
\end{tabular}

${ }^{\mathrm{a}}$ Ethyl.

${ }^{\mathrm{b}}$ Terminal; methyl attached to P.

${ }^{\mathrm{c}}$ Butyl and ethyl.

${ }^{\mathrm{d} B u t y l}$. 

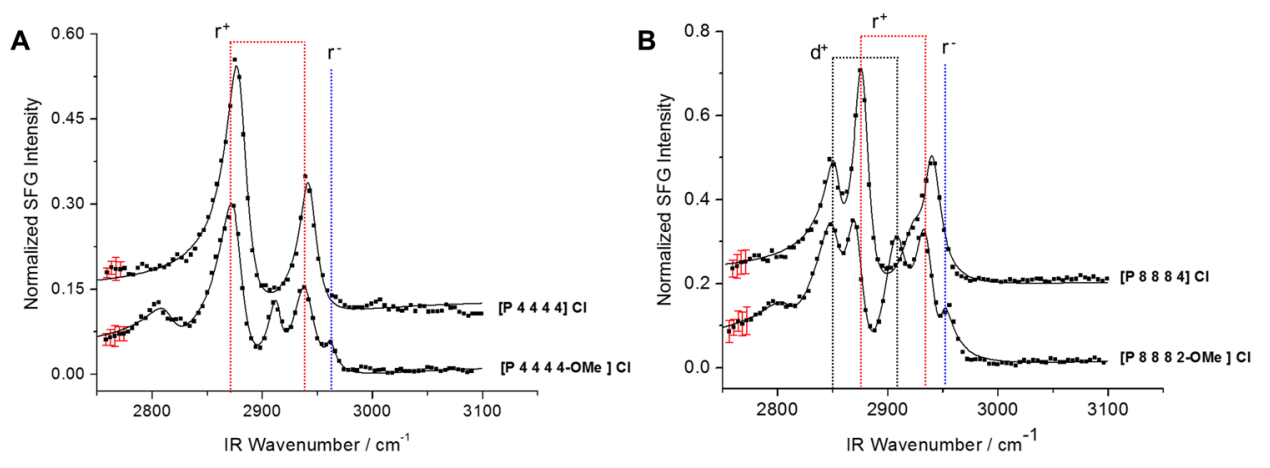

FIG. 5. (a) Sum frequency spectra $\left[\mathrm{P}_{4} 4_{4}\right][\mathrm{Cl}]$ and $\left[\mathrm{P}_{444} 4-\mathrm{OMe}\right][\mathrm{Cl}]$ at polarization combination $s s p$ offset by 0.10 and (b) sum frequency spectra of $\left[\mathrm{P}_{8} 88_{2}-\mathrm{OMe}\right][\mathrm{Cl}]$ and $\left[\mathrm{P}_{8} 88_{4}\right][\mathrm{Cl}]$ at polarization combinations $s s p$ offset by 0.20 .
$-\mathrm{OCH}_{3}$ asymmetric mode at $2913 \mathrm{~cm}^{-1}$, and the $\mathrm{r}^{-}$mode at $2961 \mathrm{~cm}^{-1}$. The $\mathrm{r}^{+}$and $\mathrm{r}_{\mathrm{FR}}^{+}$modes occurred slightly shifted to lower frequency for $\left[\mathrm{P}_{4444-\mathrm{OMe}}\right][\mathrm{Cl}]$ at $2876 \mathrm{~cm}^{-1}$ and $2939 \mathrm{~cm}^{-1}$, respectively. Figure S2 of the supplementary material displays polarization combinations ppp, sps, and pss. In ppp combination, weak $\mathrm{r}^{+}$and $\mathrm{d}^{-}$modes are observed similar to previous data with the $\mathrm{r}^{-}$mode being the most intense. This was true for $\left[\mathrm{P}_{4} 4_{44}-\mathrm{OMe}\right][\mathrm{Cl}]$; however, for $\left[\mathrm{P}_{444}\right][\mathrm{Cl}]$, the $\mathrm{r}^{-}$mode appeared particularly weak (see Fig. S3 of the supplementary material). The slight shift to lower frequency observed in the $s s p$ spectra for $\left[\mathrm{P}_{4} 444-\mathrm{OMe}\right][\mathrm{Cl}]$ compared to $\left[\mathrm{P}_{44} 4_{4}\right][\mathrm{Cl}]$ was still observed in the ppp combination. Also, the pronounced split for $\left[\mathrm{P}_{8} 88\right.$ 2-OMe $][\mathrm{Cl}]$ modes at $2950 \mathrm{~cm}^{-1}$ $\left(\mathrm{r}^{-}{ }_{i p}\right)$ and at $2964 \mathrm{~cm}^{-1}\left(\mathrm{r}^{-}{ }_{\text {op }}\right)$ was evident. This split was absent for $\left[\mathrm{P}_{44_{4}}\right][\mathrm{Cl}]$ with the weak $\mathrm{r}^{-}$mode appearing at $2965 \mathrm{~cm}^{-1}$. Finally, consistent with the previous dataset, the sps and pss combinations show the single $\mathrm{r}^{-}$mode centered at $\sim 2970 \mathrm{~cm}^{-1}$.

\section{$\left[\mathrm{P}_{8} 8\right.$ 8 2-OMe $][\mathrm{Cl}]$ and $\left[\mathrm{P}_{8} 8\right.$ 8 4$][\mathrm{Cl}]$}

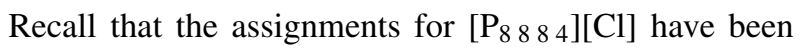
discussed in the Results and Discussion Alkyltrioctylphosphonium chloride series section and are summarized in Table II. Briefly, the $s s p$ spectra show vibrations corresponding to the $\mathrm{d}^{+}\left(\sim 2853 \mathrm{~cm}^{-1}\right), \mathrm{r}^{+}\left(\sim 2877 \mathrm{~cm}^{-1}\right), \mathrm{d}^{+} \mathrm{FR}\left(\sim 2924 \mathrm{~cm}^{-1}\right)$, and $\mathrm{r}^{+}$FR $\left(\sim 2940 \mathrm{~cm}^{-1}\right)$ modes (see Fig. S4 of the supplementary material). Apparent in the $s s p$ spectra for $\left[\mathrm{P}_{8} 8\right.$ 8 2-OMe $][\mathrm{Cl}]$ [see Fig. 5(b)] is the shift to lower frequency particularly for the $\mathrm{r}^{+}$(occurring at $2872 \mathrm{~cm}^{-1}$ ) and $\mathrm{r}^{+} \mathrm{FR}$ (occurring at $2933 \mathrm{~cm}^{-1}$ ) modes, compared to those of [ $\left.\mathrm{P}_{8} 8_{8}{ }_{4}\right][\mathrm{Cl}]$. Consequently, this difference is accompanied by the appearance of three distinct modes in the ssp spectra of $\left[\mathrm{P}_{8} 882-\mathrm{OMe}\right][\mathrm{Cl}]$, namely, the $-\mathrm{OCH}_{3}$ symmetric mode at $2810 \mathrm{~cm}^{-1}$, the $-\mathrm{OCH}_{3}$ asymmetric mode at $2908 \mathrm{~cm}^{-1}$, and the $\mathrm{r}^{-}$mode at $2948 \mathrm{~cm}^{-1}$. Figure S5 of the supplementary material displays polarization combinations ppp, sps, and pss. Note that

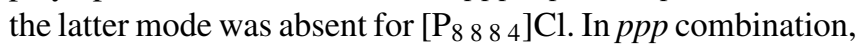
weak peaks for the $\mathrm{r}^{+}$and $\mathrm{d}^{-}$modes were evident for the two ionic liquids. The shift to lower frequency for all modes in $\left[\mathrm{P}_{8} 88\right.$ 2-OMe $][\mathrm{Cl}]$ was still observed. For the $\mathrm{r}^{-}$mode in $p p p$, the split at $2942 \mathrm{~cm}^{-1}\left(\mathrm{r}^{-}\right.$ip $)$and $2957 \mathrm{~cm}^{-1}\left(\mathrm{r}^{-}\right.$op $)$was more pronounced for $\left[\mathrm{P}_{8} 8\right.$ \& $\left.2-\mathrm{OMe}\right][\mathrm{Cl}]$. Only the $\mathrm{r}^{-}$mode dominated the spectra in both sps and pss combinations.

To investigate the effect of temperature on the surface structure, SFG spectra of $\left[\mathrm{P}_{8} 8\right.$ \& $\left.2-\mathrm{OMe}\right] \mathrm{Cl}$ were measured at
$0{ }^{\circ} \mathrm{C}$, RT $\left(20{ }^{\circ} \mathrm{C}\right)$, and $50{ }^{\circ} \mathrm{C}$. At $50{ }^{\circ} \mathrm{C}$, the same modes were observed relative to spectra at RT with similar intensity. However, when cooled to $0{ }^{\circ} \mathrm{C}$, the $\mathrm{r}^{-}$mode at $\sim 2948 \mathrm{~cm}^{-1}$ disappeared. Overall, no pronounced temperature effect was detected (see Fig. S2 of the supplementary material).

\section{Comparison of MD to SFG-Part I: Surface arrangements}

The simulation of these ionic liquids shows that the cation has a surface blocking effect on the chloride anion, which remains buried below the alkyl chains of the cation. In addition, the anion shows a close structural correlation with the central phosphorus atom, both in the surface and in the bulk, as indicated by the simulated atom density profiles in Fig. 6; this is true regardless of the alkyl chain length (Fig. 6). These density profiles represent the local atom density in the liquid bulk and at the interface; the fluctuations is owing to the characteristic of large size bulky species like the cation of these ionic liquids. However, the mass densities (Fig. S5 of the supplementary material) change monotonically at the interface without any fluctuations and show negligibly small systematic fluctuation in the bulk, which on other hand indicates the equilibrium prevailed in the ensembles. The blocking effect increases as the fourth

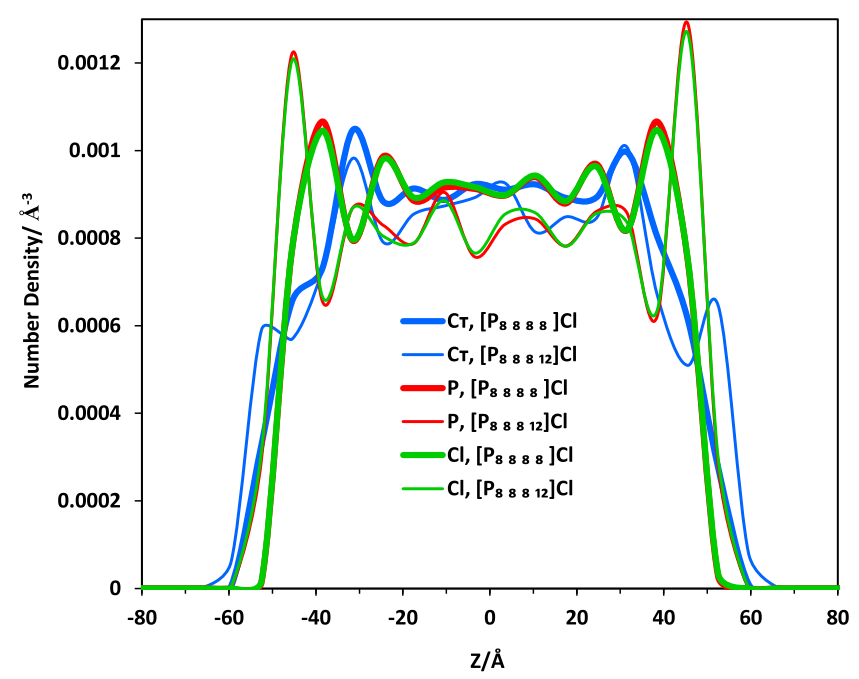

FIG. 6. Density profile of $\mathrm{C}_{\mathrm{T}}$ (terminal carbon atom), $\mathrm{P}$, and $\mathrm{Cl}$ atoms in

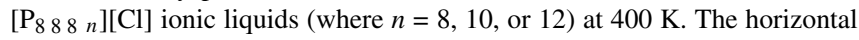
axis is adjusted accordingly for visual comparison. The case in which $n=10$ is not shown due to extensive overlap of the $\mathrm{P}$ and $\mathrm{Cl}$ plots. 
alkyl chain length increases, in the sequence $\left[\mathrm{P}_{8} 8_{8} 8\right][\mathrm{Cl}]$

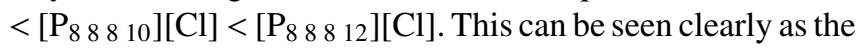
chloride anion fades out gradually from the top view (Fig. S6 of the supplementary material) as well as the side view (Fig. S7 of the supplementary material) of the surface. Under such circumstances, the chloride anion has very little influence on the vibrational spectra of the cation.

Another issue that can be addressed by the results of simulation is the barrier to the rotation of the cation in the surface region and the preferential orientation of the fourth alkyl chain which protrudes to the vapor. This barrier exists even for the

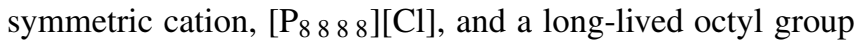
protruding to the vapor can be identified (in the simulation time period) when the location of all the four octyl group are examined in the surface region. Thus, in the SFG analysis of chain conformation and methyl group orientation, the single chain model is likely valid. In this interpretation, each cation projects one of the alkyl groups toward the gas phase (as opposed to two or three simultaneously). It might be any one of the four weighted by their relative surface energy. This means that the surface analysis is a weighted average of all four chains, not only the 4th chain. Furthermore, however, the variation in the 4th chain clearly influences the surface structure.

\section{Comparison of MD to SFG-Part II: Alkyl chain conformation}

The outcome of such preferential single chain orientation is influenced by the alkyl chain length, which can be estimated by the degree of gauche defects locally and on average over the four chains. Figure 7 shows how the average chain vector (from $\mathrm{C}$ atom attached to $\mathrm{P}$ atom to the terminal carbon atom, $\mathrm{C}_{\mathrm{T}}$ ) changes with chain length. This is used to explain the trend of SFG spectra when the fourth alkyl chain length increases, particularly for $n=8,10$, or 12 . Since each chain is essentially independent, the SFG signal is the weighted average of these orientations and conformations. The maximum in the curves from $C_{8}$ to $C_{12}$ chains suggests the later has a preferred tilt

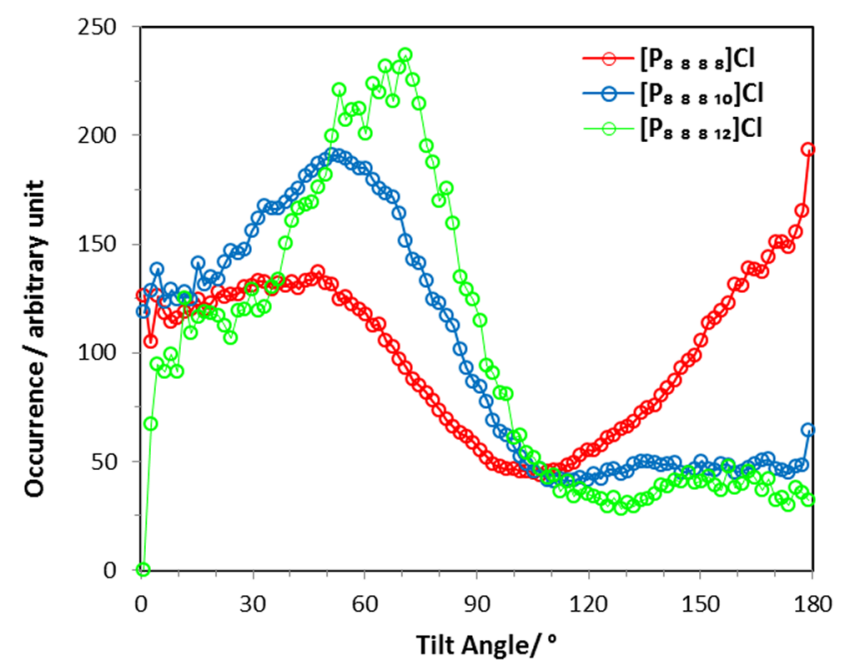

FIG. 7. Comparison of distribution of the average angles taking place (in surface and subsurface domains) between $\mathrm{C}_{1} \rightarrow \mathrm{C}_{\mathrm{T}}$ vector (of fourth alkyl chain) and the $Z$-axis of the simulation box of $\left[\mathrm{P}_{8} 8_{8} 8_{n}\right][\mathrm{Cl}]$ ionic liquids at $400 \mathrm{~K}$. Lines indicate trend lines. $\mathrm{C}_{\mathrm{T}}$ stands for terminal carbon.

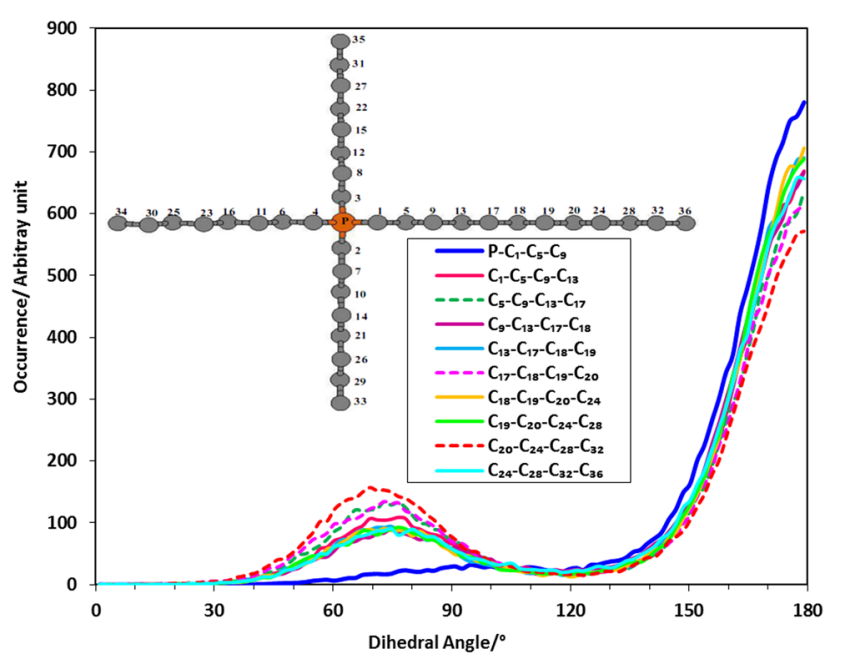

FIG. 8. The distribution of the dihedral angles along the long alkyl chain of $\left[\mathrm{P}_{8} \quad 8 \quad 8 \quad 12\right][\mathrm{Cl}]$ at $400 \mathrm{~K}$. The case which includes the phosphorus atom is also shown.

angle. Interestingly, defects are more effective with middle chain carbon atoms, and no highly stable gauche state can be identified when the $\mathrm{P}$ atom shares in the nominal torsion. Hence, the all-trans conformer is closely preserved (Fig. 8 and Fig. S8 of the supplementary material).

Furthermore, the statistical analysis based on monitoring the position of all terminal methyl groups during the simulation time shows that the four octyl groups in $\left[\mathrm{P}_{8} 8_{8} 8_{8}\right][\mathrm{Cl}]$ are equally probable to take part in the surface structure, as well as the corresponding terminal methyl group occupying the outer most region of the surface. In the same way, methyl group of

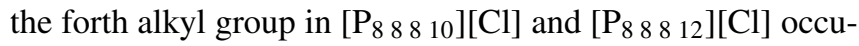
pied almost $75 \%$ and $95 \%$ of the simulation time in the outer most region of interface, respectively. Under this condition the other three methyl groups stay off the outermost of the surface. Thus, this analysis indicates that the assumption of rather independent signal from the methyl group of the fourth alkyl chain is valid. These results from the MD simulations allow for the treatment of the alkyl chains as independent and thus the single chain model for orientation and conformation analysis of the SFG spectra.

The occurrence of the dihedral angle along the alkyl chains was calculated ${ }^{47}$ from the results of MD simulation as shown in Fig. 9. Two main features are present in the plots: the all-transextended conformation with dihedral angle of $180^{\circ}$ is predominant, while the gauche conformer with a broad distribution centered at about $65^{\circ}-70^{\circ}$ is also present. The occurrence of the latter increases as the alkyl chain length increases. The simulation results clearly show that an appreciable gap in magnitude exists between the dihedral distribution in $\left[\mathrm{P}_{8} 8_{8} 8\right][\mathrm{Cl}]$ and those of the longer chains of $\left[\mathrm{P}_{8} 88{ }_{10}\right][\mathrm{Cl}]$ and $\left[\mathrm{P}_{8} 88_{12}\right][\mathrm{Cl}]$. This effect is present also in comparison to the SFG spectra: as $n$ increases, the symmetric $\mathrm{CH}_{3}$ stretching peak diminishes gradually, while that of $\mathrm{CH}_{2}$ increases. Rotation about the $\mathrm{C}-\mathrm{C}$ bond breaks the inversion symmetry of the methylene groups in the all-trans extended conformation. Overall, these observations follow the trend seen in Fig. 9. As the number of all-trans conformers (at $180^{\circ}$ ) decreases, the gauche defects similarly increase in population when the chains become 


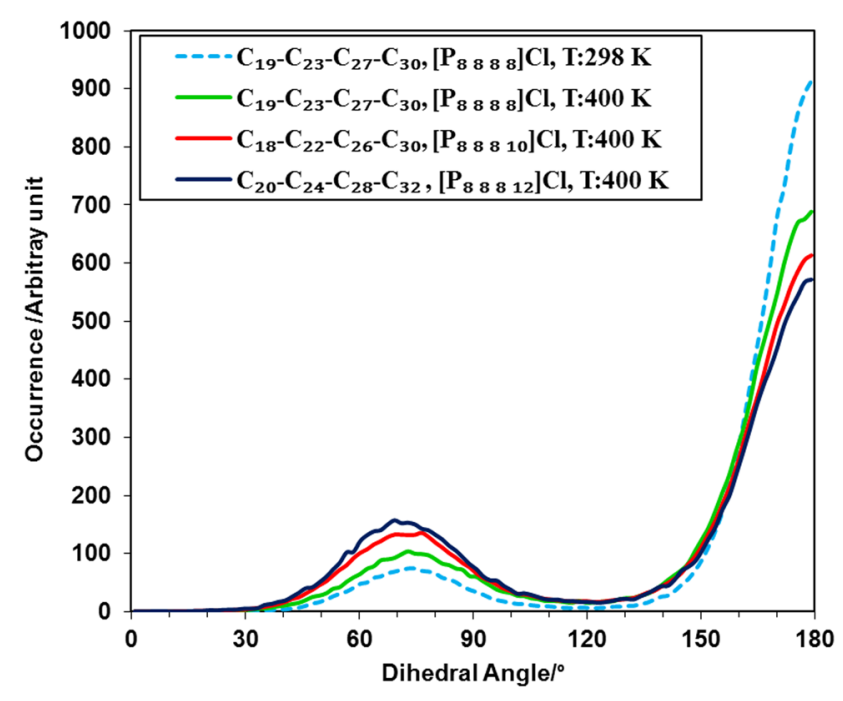

FIG. 9. Comparison of the distribution of simulated dihedral angles of the fourth (protruding) alkyl chain of $\left[\mathrm{P}_{8} 88_{8} 8\right][\mathrm{Cl}],\left[\mathrm{P}_{8} 88_{10} 10\right][\mathrm{Cl}]$, and

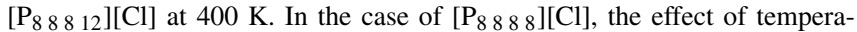
ture was tested also at $298 \mathrm{~K}$. See Fig. S8 of the supplementary material for detailed plots and atom labeling.

longer than 10 carbon atoms or when the alkyl chain length is four carbon atoms longer than an octyl $\left(\mathrm{C}_{8}\right)$ chain.

Quantum chemical calculations for a single ion-pair of each ionic liquid were performed [at the B3LYP/6-31 + g(d) level of theory] to estimate the torsional energy in regard to the gauche defect observed particularly at $65^{\circ}-70^{\circ}$ by the simulation of the three ionic liquids. As demonstrated and detailed in Fig. S9 of the supplementary material, the energy barrier to reach gauche conformer (occurs at $70^{\circ}$ ) has almost the same value for the three ionic liquids $(13.6-13.7 \mathrm{~kJ} / \mathrm{mol}$, with respect to all-trans conformer). Therefore, distribution and the probability of the gauche conformer simulated (Figs. 8 and 9 and Fig. S8 of the supplementary material) can be understood by the gas phase quantum chemical calculation and vary between the three ionic liquids slightly as dictated by the feature of the liquid state.

\section{Comparison of MD to SFG-Part III: Orientation}

The orientation analysis from SFG data of a single methyl group at the air-liquid interface is presented in Fig. 10. The

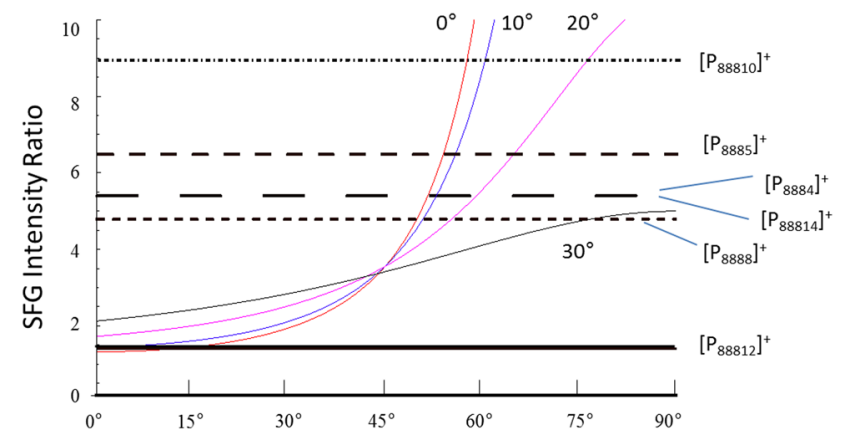

FIG. 10. Orientation analysis curve for the methyl group tilt orientation relative to the surface normal. SFG intensity refers to the ssp/sps spectra of the $\mathrm{CH}_{3}(\mathrm{sym}) /\left(\right.$ asym) ratio. Angles $0^{\circ}-30^{\circ}$ on the graph refer to the Gaussian distribution width, $\sigma$. analysis suggests that the average tilt angle for methyl groups at the surface is between $50^{\circ}$ and $60^{\circ}$ and distribution width less than $20^{\circ}$. This result seems reasonable since the tetraalkylphosphonium cations are quite complex in their surface arrangement. The two apparent exceptions to this are the symmetric cation $\left[\mathrm{P}_{8} 88_{8} \quad 12\right]^{+}$, where the SFG analysis is consistent with a larger tilt angle, close to $70^{\circ}$ and a broader distribution. It might be due to the lack of a distinguishable chain causing the overall distribution to appear broad. This also appears to be true for $\left[\mathrm{P}_{8} 88_{10}\right]^{+}$, where only a 2 carbon difference has little impact on the tilt angles at the surface. However,

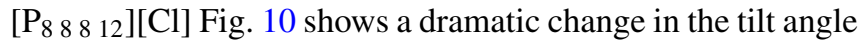
appearing nearly upright in a narrow distribution. It might be that 4 methylene unit differences from the base are enough to change the average methyl orientation at the surface. It should be noted that the $\mathrm{C}_{12}$ 4th chain shows an apparent preferred chain orientation relative to $C_{8}$ and $C_{10}$, Fig. 7 . Knowing that the occurrence of the tilt angle at $40^{\circ}$ corresponds to the maximum in the simulated profile in Fig. 7, this orientation can be attributed to a state of relative stability and is thus of the rather narrow distribution with standard deviation, $\sigma \sim 10^{\circ}$. Therefore, the simulation helps us to constrain the possible interpretation of the SFG analysis. However, the tilt angle for

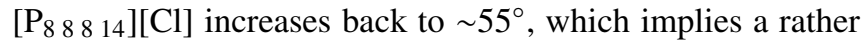
low stability of the tilt angle distribution for 6 methylene groups greater than the base $\mathrm{C}_{8}$. It is however notable that the MD simulation methyl group absolute orientations are similar to the average SFG results; however, the distributions by the simulations are significantly broader (see Figs. S1 and S10 of the supplementary material).

The tilt angle $(\theta)$ and twist angle $(\phi)$ of the alkyl terminal group $\left(\mathrm{C}_{1}-\mathrm{C}_{\mathrm{T}} \mathrm{H}_{3}\right)$ in combination with the vector $\mathbf{R}_{\mathrm{z}}$ (which coincides with the $\mathrm{C}-\mathrm{C}$ bond) are used to represent the molecular fixed polar coordinate (Fig. 11)

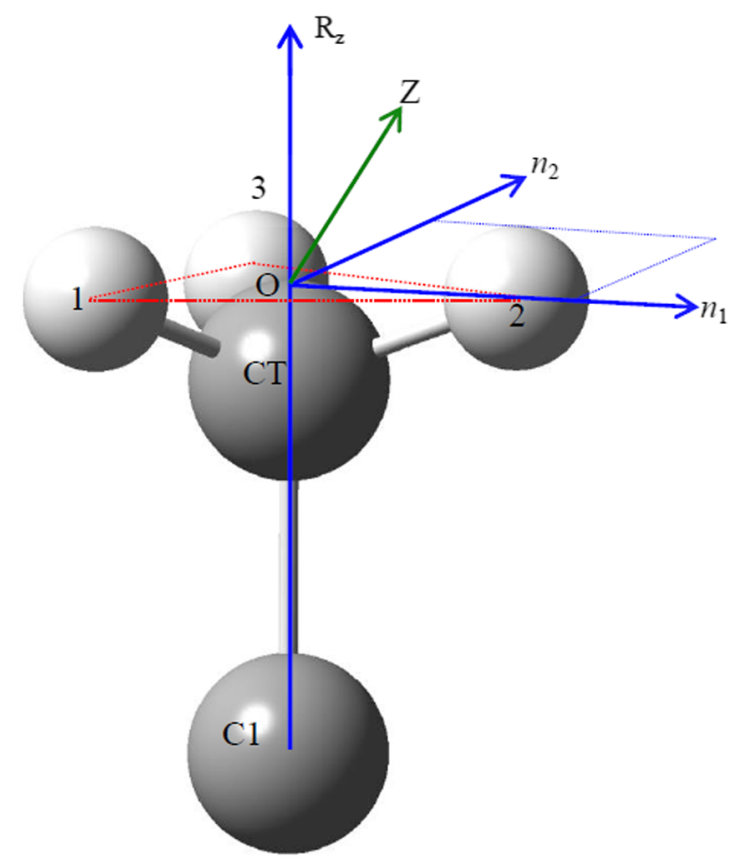

FIG. 11. Molecular fixed polar coordinate for modeling the orientation of the surface SFG-active terminal alkyl group. Vector $\mathbf{Z}$ is normal of the surface ensemble. 
and model the orientation of this ionic liquid SFG-active group. By definition, $\theta$ is the angle between the normal of the ensemble $(\mathrm{Z})$ and the $\mathbf{R}_{\mathrm{Z}}$ vector; ${ }^{48,49} \phi$ is the angle between the $\mathbf{Z}$ projection-vector onto the $n_{1}-n_{2}$ plane and $\boldsymbol{n}_{1}$ vector and represents the $\mathrm{C}_{3}$ rotation. Considering trajectories of all atoms in $\mathrm{C}_{1}-\mathrm{C}_{\mathrm{T}} \mathrm{H}_{3}$ only, within the narrow surface region over the simulation time, the variation

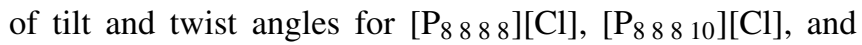
$\left[\begin{array}{llll}\mathrm{P}_{8} & 8 & 8 & 12\end{array}\right][\mathrm{Cl}]$ leads to the maps shown in Figs. 12(a)-12(c), respectively.

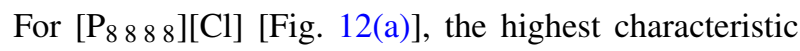
probability is seen at $\cos (\theta)=0.7\left(\sim 45^{\circ}\right)$, particularly at three spot points: $\phi=0^{\circ}, 40^{\circ}$, and $75^{\circ}$. More importantly, at about $\cos (\theta)=0$, probability is inappreciable and featureless; notably the feature is lost completely for $\cos (\theta)<0$. This implies that the tilt angle of the $\mathrm{C}_{1}-\mathrm{C}_{\mathrm{T}}$ bond is centered at $45^{\circ}$ and the twisting of the $\mathrm{C}_{\mathrm{T}} \mathrm{H}_{3}$ angle is centered at three angles. Analysis of

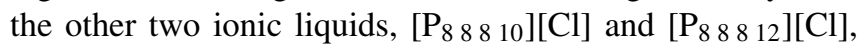
leads to the same conclusion, although each ionic liquid demonstrates characteristic tilting and twisting profiles. For

\section{$\left[\mathrm{P}_{8} 888\right.$ 8 $] \mathrm{Cl}$}

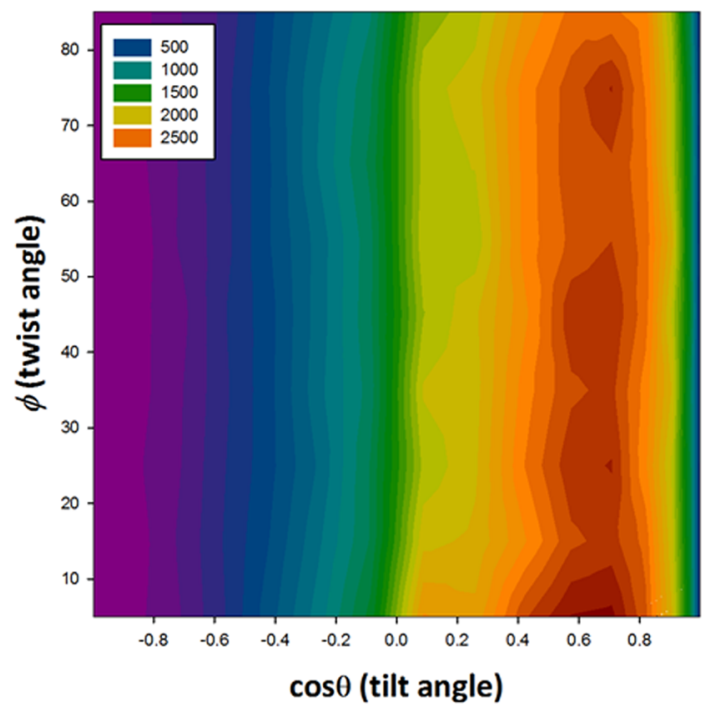

(a)

(c)

\section{$[\mathrm{P} 888$ 8 12]Cl}

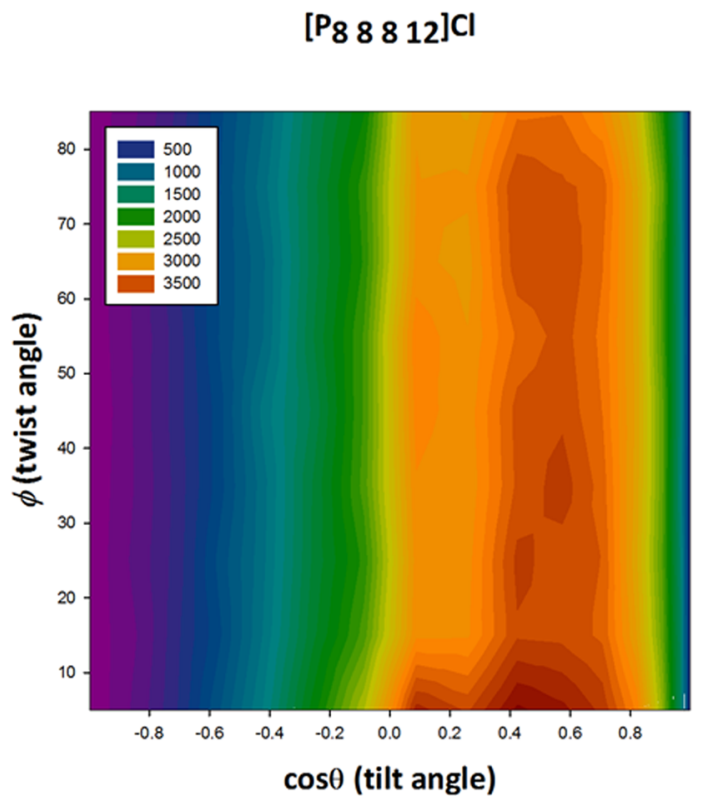

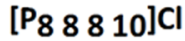

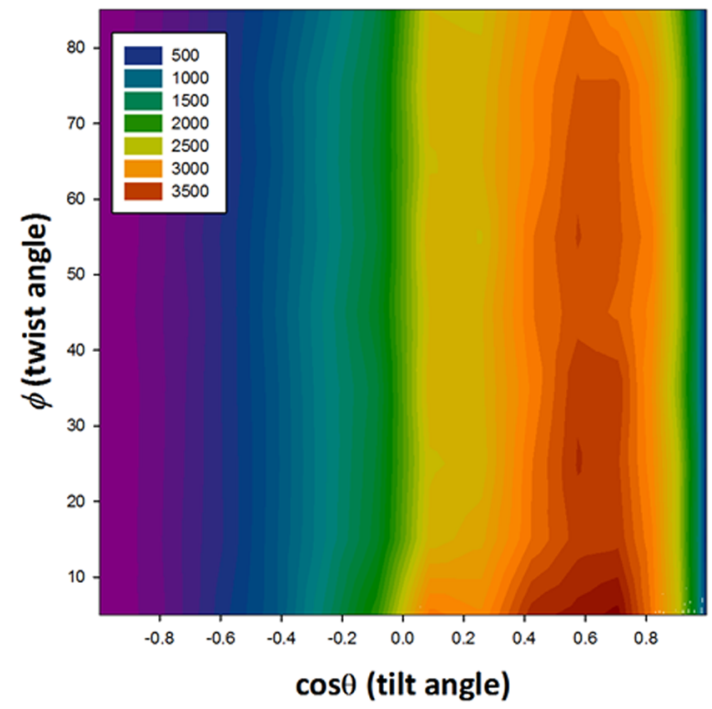

(b)

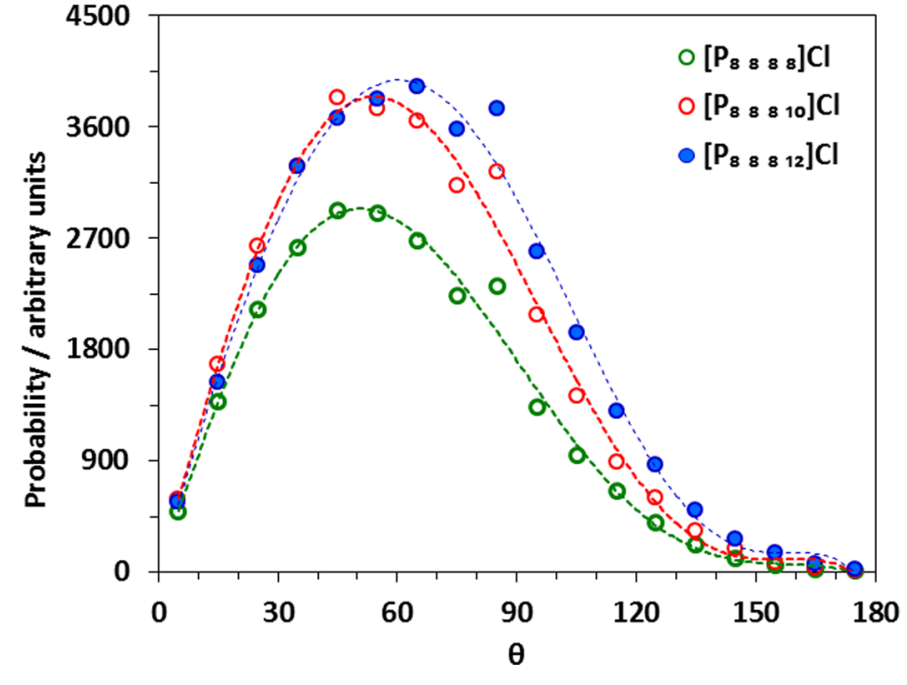

(d)

FIG. 12. Simulation results on the orientation of the terminal methyl group tilt $(\theta)$ and twist $(\phi)$ angles at the air-ionic liquid interface for $\left[\mathrm{P}_{8} 88 n\right][\mathrm{Cl}]$ : (a) $n=8$, (b) $n=10$, (c) $n=12$, and (d) average tilt angle ( $\theta$ ) after integration about the twist angle $(\phi)$. 
[ $\mathrm{P}_{8} 8$ 1 $\left._{10}\right][\mathrm{Cl}]$ [Fig. 12(b)], the above profile is less organized, while $\left[\mathrm{P}_{8} \quad 8 \quad 8\right.$ 12] $[\mathrm{Cl}]$ [Fig. 12(c)] is relatively more defined and organized. The probability depicted by the maps are in such

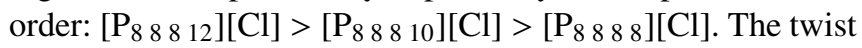
angle, $\phi$, was not determined in these SFG measurements.

Examination of the maps in Fig. 12 demonstrates $\mathrm{C}_{\mathrm{T}} \mathrm{H}_{3}$ twisting, which is characteristic in all three ionic liquids and is highly dependent on the tilt angle [Fig. 12(d)]. Twisting is likely if the tilt angle is not too high and only occurs when the highest probability of the tilt angle is, for instance, around $45^{\circ}$. This diminishes if the tilt angle is too low. Noting that $\mathrm{CH}_{3}$ can be found at a certain twist angle with higher probability implies a barrier to $\mathrm{C}_{3}$ rotation with the quantization understandable in terms of conformational change. What makes these hydrocarbon chains SFG-active is the tilt angle dependency of the $\mathrm{C}_{\mathrm{T}} \mathrm{H}_{3}$ twist revealed by the molecular dynamics simulation.

\section{Detailed discussion}

SFG spectra of the alkyltrioctylphosphonium chloride,

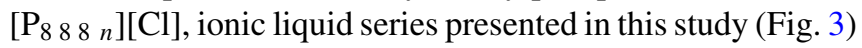
showed that when the fourth alkyl chain length is sufficiently long $(n=12$ and 14), the ionic liquids exhibited increased conformational disorder in the form of gauche defects. This is most directly observed by the increase in the $\mathrm{CH}_{2}$ (sym)/ $\mathrm{CH}_{3}$ (sym) peak ratio. Overall the longer chain also resulted in a change in the average tilt orientation of the terminal methyl group. This was evidenced by the appearance of the $\mathrm{r}^{-}$mode in the $s s p$ combination and the $\mathrm{r}^{-}$mode split observed in the ppp com-

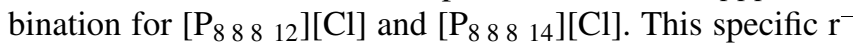
mode feature in these two ionic liquids was otherwise absent in other members of the $\left[\mathrm{P}_{8} 8_{8} n\right][\mathrm{Cl}]$ series, where $n=4,5,8$, and 10 . Note that $\left[\mathrm{P}_{8} \quad 8_{8} 8{ }_{8}\right][\mathrm{Cl}]$ represented the fully symmetrical cation in the series such that a two-carbon difference in the fourth alkyl chain from the fully symmetrical $\left[\mathrm{P}_{8}\right.$ \& $\left._{8} 8\right][\mathrm{Cl}]$ did not create the same effect as the four-carbon chain length difference from $\left[\mathrm{P}_{8} \mathrm{~B}_{8}{ }_{8}\right][\mathrm{Cl}]$. This observation suggests that the octyl chains are having the major contribution to the surface, while the $\mathrm{C}_{10}$ through $\mathrm{C}_{14}$ impact the surface relatively

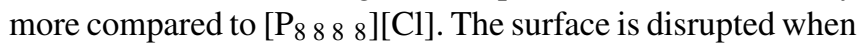
the fourth alkyl chain is sufficiently lengthened to at least four

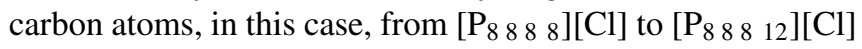
or to $\left[\mathrm{P}_{8} 8{ }_{8}{ }_{14}\right][\mathrm{Cl}]$.

Interpretations of the SFG data alone were ambiguous; the signal could be from multiple chains from one cation projecting toward the surface or from a mixture of single chains from each phosphorus atom center in the ionic liquid. Combined with MD simulations, the SFG results were found to be consistent with the latter. All SFG data showed $\mathrm{C}-\mathrm{H}$ spectra from each of the four alkyl chains. This is especially apparent in the $\left[\mathrm{P}_{1224}\right]\left[\mathrm{NTf}_{2}\right]$ (Fig. 4, where the $\mathrm{P}-\mathrm{CH}_{3}$ peak is assigned). Similarly, the $\left[\mathrm{P}_{8} \quad 8_{8} \quad n\right][\mathrm{Cl}]$ ionic liquids with unique terminal groups (-CN in Fig. 4 and $-\mathrm{OCH}_{3}$ in Fig. 5) showed significant $\mathrm{C}-\mathrm{H}$ spectra; specifically, characteristic $-\mathrm{OCH}_{3}$ group vibrational modes were obvious for $\left[\mathrm{P}_{4} 444_{-} \mathrm{OMe}\right][\mathrm{Cl}]$. This, in addition to the MD results on the lifetime of each chain at the surface, provides a basic model for describing the alkyl group orientation at the gas-liquid interface. The MD simulations are compatible with the orientation angles determined by SFG measurements, which supports the accuracy of the simulation in interpreting the surface structure of the ionic liquid surface [compare Figs. 10 and 12(d)].

For ionic liquids $\left[\mathrm{P}_{8} 88\right.$ 5-CN $] \mathrm{Br}$ and $\left[\mathrm{P}_{6663-\mathrm{CN}}\right] \mathrm{Br}$, spectra in the $\mathrm{C}-\mathrm{H}$ stretching region (Fig. 4) were identical to those of the $\left[\mathrm{P}_{8} 8_{8 n}\right][\mathrm{Cl}]$ series, where $n=4,5,8$, or 10 . This was accompanied by the absence of characteristic modes for the $-\mathrm{C} \equiv \mathrm{N}$ group (spectra investigated but not shown in this report) attached to the cation in 5-cyanopentyl (for $\left[\mathrm{P}_{8} 88\right.$ 5-CN $] \mathrm{Br}$ ) and 3-cyanopropyl (for [ $\left.\mathrm{P}_{66} 663-\mathrm{CN}\right] \mathrm{Br}$ ). This was not surprising, as the much weaker $\mathrm{C} \equiv \mathrm{N}$ stretching mode compared to the $\mathrm{C}-\mathrm{H}$ stretching mode could easily be buried, especially in systems where low surface conformational ordering is expected (due to the presence of long trioctyl and trihexyl chains), which is the case for these two. For the $\mathrm{C} \equiv \mathrm{N}$ mode to be visible, the rigid requirement of a well-oriented $-\mathrm{C}_{5} \mathrm{C} \equiv \mathrm{N}$ or $-\mathrm{C}_{3} \mathrm{C} \equiv \mathrm{N}$ group at the surface would have to be satisfied, which in these samples are quite unlikely.

In the case of $\left[\mathrm{P}_{666614}\right]\left[\mathrm{B}(\mathrm{CN})_{4}\right]$, obvious deviations from the typical $\left[\mathrm{P}_{8} \quad 8 \quad\right.$ \& $\left.n\right][\mathrm{Cl}]$ series spectra $(n<12)$ but similar for $\mathrm{n} \geq 12$ emerged (Fig. 4). While in the $\left[\mathrm{P}_{8} 8_{8}{ }_{n}\right][\mathrm{Cl}]$ series $(n<12)$ the $\mathrm{d}^{+}$mode is approximately half the intensity of the $\mathrm{r}^{+}$mode, this marked difference is lost in $\left[\mathrm{P}_{666}\right.$ 14 $\left._{14}\right]\left[\mathrm{B}(\mathrm{CN})_{4}\right]$. In the latter salt, the $\mathrm{r}^{+}$mode is decreased to about half the intensity (compared to $\left[\mathrm{P}_{8} 8_{8} 8\right][\mathrm{Cl}]$ ), resulting in the intensity of the $\mathrm{r}^{+}$mode matching the intensity of the $\mathrm{d}^{+}$mode. This overall decrease in the $\mathrm{r}^{+}$mode intensity suggests that $\left[\mathrm{P}_{666614}\right]\left[\mathrm{B}(\mathrm{CN})_{4}\right]$ displays more conformational disorder,

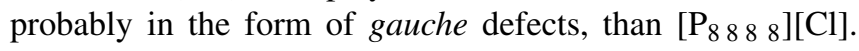
This is probably due to the presence of a long tetradecyl chain among the trihexyl chains attached to phosphorus, which highly distorts the molecular symmetry. Knowing this, it is important to mention that using previous estimations by Rebelo, Coutinho, and co-workers, ${ }^{7,50}$ the molecular volume of $\left[\mathrm{P}_{66614}\right]^{+}$at $947 \AA^{3}$ is equal to that of $\left[\mathrm{P}_{8888}\right]^{+}$. However, the molecular orientation effectively dictates the surface structure more than the molecular size, as the SFG results reveal. Furthermore, the fact is that $\left[\mathrm{B}(\mathrm{CN})_{4}\right]^{-}$is a bulkier anion (molecular volume $\left.=143 \AA^{3}\right)^{51}$ compared to $\mathrm{Cl}^{-}$(molecular volume $\left.=24 \AA^{3}\right),{ }^{52,53}$ which may indicate that increased interionic distance between the central phosphorus atom and the anion can be expected in $\left[\mathrm{P}_{6} 66_{14}\right]\left[\mathrm{B}(\mathrm{CN})_{4}\right]$ compared to $\left[\mathrm{P}_{8} 88_{8} 8\right][\mathrm{Cl}]$. This, in addition to the steric constraints from bulky alkyl substituents in the cation, contributes to a more disordered surface structure for ionic liquids with a long chain. However, the anion appears to have little perturbation on the surface structure of these ionic liquids.

Thus, it can be concluded based upon these data that the cation spectra reveal a surface populated by all four alkyl groups attached to the phosphonium cation (Figs. 4 and 5). The appearance of specific features from shorter alkyl chain $v s$. longer alkyl chain groups distinguishable from each other serves to support this observation. For instance, Fig. 4 shows vibrational modes of the butyl, ethyl, and terminal methyl groups of $\left[\begin{array}{lll}\mathrm{P}_{1} 2_{2} & 4\end{array}\right]\left[\mathrm{NTf}_{2}\right]$ which are clearly discernible in the spectra. Specifically, the presence of the unique $\mathrm{P}-\mathrm{CH}_{3}$ mode suggests that the chains appear at the surface quite randomly 
(single-chain model), as this mode is not as low energy as the other butyl or ethyl chains. Because of the presence of the terminal methyl group and much shorter chains compared to the rest of the samples studied here, $\left[\mathrm{P}_{12} 2_{24}\right]\left[\mathrm{NTf}_{2}\right]$ has significantly less steric encumbrance around the central phosphorus atom and represents the most unsymmetrical cation. The lowest intensities in SFG spectra were observed for the $\left[\begin{array}{llll}\mathrm{P}_{1} & 2 & 2 & 4\end{array}\right]^{+}$cation, suggesting a highly disordered structure, which was expected.

As mentioned, Fig. 5 showed methoxy-functionalized tetraalkylphosphonium chlorides, $\left[\mathrm{P}_{8} 88\right.$ 8 $\left.2-\mathrm{OMe}\right][\mathrm{Cl}]$ and $\left[\mathrm{P}_{4444-\mathrm{OMe}}\right][\mathrm{Cl}]$, displaying features of the unique substituents attached to the central phosphorus atom, namely, 2methoxyethyl $\left(-\mathrm{C}_{2} \mathrm{H}_{4} \mathrm{OMe}\right)$ and 4-methoxybutyl $\left(-\mathrm{C}_{4} \mathrm{H}_{8} \mathrm{OMe}\right)$. Individual spectral profiles of these two independent cases indicate that, for the unique chains to be detected at the surface, 2-methoxyethyl in $\left[\mathrm{P}_{8} 88\right.$ 2-OMe $][\mathrm{Cl}]$ and 4-methoxybutyl in $\left[\mathrm{P}_{4444-\mathrm{OMe}}\right][\mathrm{Cl}]$ must be close enough in surface energy as their purely alkyl chain equivalent, $\left[\mathrm{P}_{8} 8_{8} 8_{4}\right][\mathrm{Cl}]$ and $\left[\mathrm{P}_{4444}\right][\mathrm{Cl}]$, respectively. Contact angle measurements ${ }^{54,55}$ using self-assembled monolayers (SAMs) on various metal substrates reveal slightly lower water contact angles for SAMs modified slightly by introducing a terminal $-\mathrm{OCH}_{3}$ group $v s$. SAMs of purely alkyl groups. This implies a higher surface free energy for those with terminal $-\mathrm{OCH}_{3}$ groups $v s$. purely alkane equivalents. The higher surface free energy may serve as the driving force for the fourth alkyl substituent containing a methoxy group to appear slightly less at the surface, randomly along with the other three alkyl chains attached to the phosphorus atom. Therefore, a random mixture of methoxy-functionalized and purely alkyl chains attached to the phosphorus atom must appear at the liquid surface.

While the specific features of the unique methoxycontaining substituent are detected, it is beyond the scope of these experiments to distinguish separately the contributions of the trioctyl or tributyl chains $v s$. the single methoxycontaining group. Ultimately, the presence of a terminal $-\mathrm{OCH}_{3}$ group sufficiently distorts the surface structure, as seen in the decrease of the $\mathrm{r}^{+}$mode intensity in $\left[\mathrm{P}_{8} 8\right.$ 8 $\left.2-\mathrm{OMe}\right][\mathrm{Cl}]$, to almost half its original intensity than in $\left[\mathrm{P}_{8} 8_{8} 8_{4}\right][\mathrm{Cl}]$, as well as the slight, but obvious decrease in intensity of the $\mathrm{r}^{+}$mode in $\left[\mathrm{P}_{4444-\mathrm{OMe}}\right][\mathrm{Cl}]$ relative to $\left[\mathrm{P}_{4444}\right][\mathrm{Cl}]$. The clear appearance of the $\mathrm{r}^{-}$mode in $\left[\mathrm{P}_{4444-\mathrm{OMe}}\right][\mathrm{Cl}]$ vs. its absence in $\left[\mathrm{P}_{4444-\mathrm{OMe}}\right][\mathrm{Cl}]$ is further indication of gauche defects.

\section{CONCLUSION}

SFG spectroscopy results in conjunction with MD simulations provide a more detailed picture of the gas-liquid interface for tetraalkylphosphonium ionic liquids. They have single chains from each of the phosphonium centers projecting to the gas phase. However, there is a nearly equal probability for any one of the four alkyl groups to be present. Furthermore, the experimental data and computations show that the chains are relatively disordered with a high degree of conformational motion possible.

\section{SUPPLEMENTARY MATERIAL}

See supplementary material for more detailed description of sample preparations, MD simulation details, and polarization spectra of the SFG spectroscopy.

\section{ACKNOWLEDGMENTS}

S.B. thanks the Welch Foundation (Grant No. E-1531) and N.V.P., K.R.S., and G.A. thank Cytec Canada, for support of the project. Computer time provided in part by the University of Houston uHPC founded by NSF (Award No. ACI: 1531814) and Institute for Research in Fundamental Sciences (IPM) is greatly acknowledged. M.H.G. thanks the University of Houston for granting his sabbatical leave during January to September 2017 and support by INSF (Grant No. 93044214). This article is dedicated to our friend and coauthor K.R.S. whose enthusiasm and guidance in science will be very much missed.

${ }^{1}$ C. J. Bradaric, A. Downard, C. Kennedy, A. J. Robertson, and Y. Zhou, Green Chem. 5(2), 143-152 (2003).

${ }^{2}$ T. J. Wooster, K. M. Johanson, K. J. Fraser, D. R. MacFarlane, and J. L. Scott, Green Chem. 8(8), 691-696 (2006).

${ }^{3}$ A. Flemming, M. Hoffmann, and M. Köckerling, Z. Anorg. Allg. Chem. 636(3-4), 562-568 (2010).

${ }^{4}$ X. Liu, F. Zhou, Y. Liang, and W. Liu, Wear 261(10), 1174-1179 (2006).

${ }^{5}$ V. Ermolaev, V. Miluykov, I. Rizvanov, D. Krivolapov, E. Zvereva, S. Katsyuba, O. Sinyashin, and R. Schmutzler, Dalton Trans. 39(23), 5564-5571 (2010).

${ }^{6}$ G. Adamova, R. L. Gardas, M. Nieuwenhuyzen, A. V. Puga, L. P. N. Rebelo, A. J. Robertson, and K. R. Seddon, Dalton Trans. 41(27), 8316-8332 (2012).

${ }^{7}$ G. Adamová, R. L. Gardas, L. P. N. Rebelo, A. J. Robertson, and K. R. Seddon, Dalton Trans. 40(47), 12750-12764 (2011).

${ }^{8}$ K. Tsunashima and M. Sugiya, Electrochem. Commun. 9(9), 2353-2358 (2007).

${ }^{9}$ K. Tsunashima, A. Kawabata, M. Matsumiya, S. Kodama, R. Enomoto, M. Sugiya, and Y. Kunugi, Electrochem. Commun. 13(2), 178-181 (2011).

${ }^{10}$ K. J. Fraser and D. R. MacFarlane, Aust. J. Chem. 62(4), 309-321 (2009).

${ }^{11}$ G. Adamova, J. N. Canongia-Lopes, L. P. Rebelo, L. M. Santos, K. R. Seddon, and K. Shimizu, Phys. Chem. Chem. Phys. 16(9), 4033-4038 (2014).

${ }^{12}$ R. Byrne, S. Coleman, S. Gallagher, and D. Diamond, Phys. Chem. Chem. Phys. 12(8), 1895-1904 (2010).

${ }^{13}$ Z. Breitbach and D. Armstrong, Anal. Bioanal. Chem. 390(6), 1605-1617 (2008).

${ }^{14}$ P. Mukherjee, J. A. Crank, P. S. Sharma, A. B. Wijeratne, R. Adhikary, S. Bose, D. W. Armstrong, and J. W. Petrich, J. Phys. Chem. B 112(11), 3390-3396 (2008).

${ }^{15}$ A. G. M. Ferreira, P. N. Simoes, A. F. Ferreira, M. A. Fonseca, M. S. A. Oliveira, and A. S. M. Trino, J. Chem. Thermodyn. 64, 80-92 (2013).

${ }^{16}$ J. Martak, S. Schlosser, and M. Blahusiak, Chem. Pap. 65(5), 608-619 (2011).

${ }^{17}$ M. S. Calado, G. R. Ivanis, J. M. Vuksanovic, M. L. Kijevcanin, S. P. Serbanovic, and Z. P. Visak, Fluid Phase Equilib. 344, 6-12 (2013).

${ }^{18} \mathrm{~S}$. Wellens, B. Thijs, and K. Binnemans, Green Chem. 14(6), 1657-1665 (2012).

${ }^{19}$ Y. Liu, L. Guo, L. Zhu, X. Sun, and J. Chen, Chem. Eng. J. 158(2), 108-114 (2010).

${ }^{20}$ M. Regel-Rosocka, L. Nowak, and M. Wisniewski, Sep. Purif. Technol. 97, 158-163 (2012).

${ }^{21}$ A. Fan, G.-K. Chuah, and S. Jaenicke, Catal. Today 198(1), 300-304 (2012).

${ }^{22}$ H. A. Kalviri and F. M. Kerton, Green Chem. 13(3), 681-686 (2011).

${ }^{23}$ H. A. Kalviri and F. M. Kerton, Adv. Synth. Catal. 353(17), 3178-3186 (2011).

${ }^{24}$ Y. Kunugi, N. Hamada, S. Kodama, M. Sugiya, and K. Tsunashima, Electrochemistry 79(10), 810-812 (2011). 
${ }^{25}$ J. E. F. Weaver, D. Breadner, F. Deng, B. Ramjee, P. J. Ragogna, and R. W. Murray, J. Phys. Chem. C 115(39), 19379-19385 (2011).

${ }^{26}$ A. E. Somers, P. C. Howlett, J. Sun, D. R. MacFarlane, and M. Forsyth, Tribology and Design, Volume 66 of WIT Transactions on Engineering Sciences (WIT Press, 2010), pp. 273-283.

${ }^{27}$ R. K. Blundell and P. Licence, Phys. Chem. Chem. Phys. 16, 15278 (2014).

${ }^{28}$ Y. R. Shen, in Nonlinear Spectroscopy for Molecular Structure Determination, edited by R. W. Field (Blackwell, Oxford, UK, 1998), pp. 249-271.

${ }^{29}$ H.-F. Wang, W. Gan, R. Lu, Y. Rao, and B.-H. Wu, Int. Rev. Phys. Chem. 24(2), 191-256 (2005).

${ }^{30}$ M. J. Shultz, Adv. Multi-Photon Processes Spectrosc. 18, 133-199 (2008).

${ }^{31}$ Y. R. Shen, J. Phys. Chem. C 116(29), 15505-15509 (2012).

${ }^{32}$ X. Zhuang, P. B. Miranda, D. Kim, and Y. R. Shen, Phys. Rev. B 59(19), 12632-12640 (1999).

${ }^{33}$ R. Lu, W. Gan, B.-H. Wu, Z. Zhang, Y. Guo, and H.-F. Wang, J. Phys. Chem. B 109(29), 14118-14129 (2005).

${ }^{34}$ C. Y. Peñalber, Z. Grenoble, G. A. Baker, and S. Baldelli, Phys. Chem. Chem. Phys. 14(15), 5122-5131 (2012).

${ }^{35}$ C. Aliaga and S. Baldelli, J. Phys. Chem. B 111(33), 9733-9740 (2007).

${ }^{36}$ S. Baldelli, Acc. Chem. Res. 41(3), 421-431 (2008).

${ }^{37}$ S. Baldelli, J. Phys. Chem. B 107(25), 6148-6152 (2003).

${ }^{38}$ M. J. Frisch, G. W. Trucks, H. B. Schlegel, G. E. Scuseria, M. A. Robb, J. R. Cheeseman, G. Scalmani, V. Barone, B. Mennucci, G. A. Petersson, H. Nakatsuji, M. Caricato, X. Li, H. P. Hratchian, A. F. Izmaylov, J. Bloino, G. Zheng, J. L. Sonnenberg, M. Hada, M. Ehara, K. Toyota, R. Fukuda, J. Hasegawa, M. Ishida, T. Nakajima, Y. Honda, O. Kitao, H. Nakai, T. Vreven, J. J. A. Montgomery, J. E. Peralta, F. Ogliaro, M. Bearpark, J. J. Heyd, E. Brothers, K. N. Kudin, V. N. Staroverov, R. Kobayashi, J. Normand, K. Raghavachari, A. Rendell, J. C. Burant, S. S. Iyengar, J. Tomasi, M. Cossi, N. Rega, J. M. Millam, M. Klene, J. E. Knox, J. B. Cross, V. Bakken, C. Adamo, J. Jaramillo, R. Gomperts, R. E. Stratmann, O. Yazyev, A. J. Austin, R. Cammi, C. Pomelli, J. W. Ochterski, R. L. Martin, K. Morokuma, V. G. Zakrzewski, G. A. Voth, P. Salvador,
J. J. Dannenberg, S. Dapprich, A. D. Daniels, O. Farkas, J. B. Foresman, J. V. Ortiz, J. Cioslowski, and D. J. Fox, Gaussian 09, Revision A.02, Gaussian, Inc., Wallingford, CT, 2009.

${ }^{39}$ W. Smith and T. R. Forester, J. Mol. Graphics 14, 136-141 (1996).

${ }^{40}$ W. L. Jorgensen, D. S. Maxwell, and J. Tirado-Rives, J. Am. Chem. Soc. 118, 11225-11236 (1996).

${ }^{41}$ L. Gontrani, O. Russina, F. L. Celso, R. Caminiti, G. Annat, and A. Triolo, J. Phys. Chem. B 113, 9235-9240 (2009).

${ }^{42}$ C. Aliaga, G. A. Baker, and S. Baldelli, J. Phys. Chem. B 112(6), 1676-1684 (2008).

${ }^{43}$ D. C. McKean, G. P. McQuillan, W. F. Murphy, and F. Zerbetto, J. Phys. Chem. 94(12), 4820-4831 (1990).

${ }^{44}$ C. S. Santos and S. Baldelli, J. Phys. Chem. B 111(18), 4715-4723 (2007).

${ }^{45}$ C. S. Santos and S. Baldelli, J. Phys. Chem. B 113(4), 923-933 (2009).

${ }^{46}$ R. N. Ward, D. C. Duffy, P. B. Davies, and C. D. Bain, J. Phys. Chem. 98(34), 8536-8542 (1994).

${ }^{47}$ M. Brehm and B. Kirchner, J. Chem. Inf. Model. 51, 2007-2023 (2011).

${ }^{48}$ M. H. Ghatee, A. R. Zolghadr, F. Moosavi, and L. Pakdel, J. Chem. Phys. 34, 074707 (2011).

${ }^{49}$ M. Jorge, P. Jedlovszky, and M. N. Cordeiro, J. Phys. Chem. C 114, 11169-11179 (2010).

${ }^{50}$ R. L. Gardas and J. A. P. Coutinho, Fluid Phase Equilib. 263(1), 26-32 (2008).

${ }^{51}$ N. Sanchez-Ramirez, V. L. Martins, R. A. Ando, F. F. Camilo, S. M. Urahata, M. C. C. Ribeiro, and R. M. Torresi, J. Phys. Chem. B 118(29), 8772-8781 (2014).

${ }^{52}$ C. M. S. S. Neves, P. J. Carvalho, M. G. Freire, and J. A. P. Coutinho, J. Chem. Thermodyn. 43(6), 948-957 (2011).

${ }^{53}$ L. I. N. Tome, R. L. Gardas, P. J. Carvalho, M. J. Pastoriza-Gallego, M. M. Pineiro, and J. A. P. Coutinho, J. Chem. Eng. Data 56(5), 2205-2217 (2011).

${ }^{54}$ P. E. Laibinis and G. M. Whitesides, J. Am. Chem. Soc. 114(6), 1990-1995 (1992).

${ }^{55}$ P. E. Laibinis, C. D. Bain, R. G. Nuzzo, and G. M. Whitesides, J. Phys. Chem. 99(19), 7663-7676 (1995). 